\title{
Research Paper \\ Evaluating the Objective and Subjective Effects of Annexation of Nourabad Villages to the City in Lorestan Province, Iran: A Case Study
}

\author{
Masoud Safaee Pour ${ }^{1},{ }^{*}$ Hossein Mansourian², Ali Keumarsi ${ }^{3}$
}

1. Associate Professor, Department of Geography and Urban Planning, School of Earth Sciences, Shahid Chamran University of Ahvaz, Ahvaz, Iran

2. Assistant Professor, Department of Human Geography, Faculty of Geography, University of Tehran, Tehran, Iran.

3. MA Student, Department of Geography and Urban Planning, School of Earth Sciences, Shahid Chamran University of Ahvaz, Ahvaz, Iran.

Received: 03 Sep. 2016 Accepted: 11 Dec. 2016

Key words: Annexation village to city, Objective and subjective effects, Nourabad
Citation: Safaee Pour, M., Mansourian, H., \& Keumarsi, A. (2017). [Evaluating the Objective and Subjective Effects of Inserting Villages Into Towns (Case Study: Nourabad's Surrounding Villages) (Persian)]. Journal of Rural Research, 8(1), 122-137. http://dx.doi.org/10.21859/jjr-08018

http://dx.doi.org/10.21859/jjr-08018

\begin{abstract}
A B STRACT
Rapid urban population growth of Iran in recent decades, has expanded physical boundaries of cities and annexation of rural settlements around the cities within the formal boundaries of cities. The annexation and integration of surrounding villages in the city, according to the spatial and temporal conditions has unique features and effects. Therefore, this study aimed to evaluate the social, economic, environmental, and spatial effects of annexation of four villages of Kazem Abad, Karim Abad, Khalifa, and Khani Abad to Nurabad City in Lorestan Province. To achieve the objectives of this study we used the results of the general census of population and housing, satellite images, and data obtained from household surveys using a researcher-made questionnaire. The results show that the adjunction of villages to cities is a complex, multi-dimensional and multi-stage process, which according to spatial and temporal conditions need specific measures. Evaluating the subjective effects of annexation show that in most indicators, the conditions of local residents have improved after the annexation. Among the components of factor analysis, four components of physical condition of village, the level of production and motivation in agriculture and livestock activities, access to facilities and infrastructures are the most important predictors for the level of satisfaction from annexation of village to city.
\end{abstract}

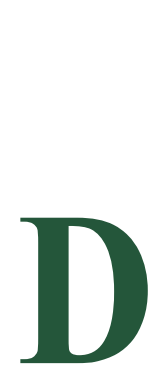

\section{Extended Abstract}

\section{Introduction}

uring recent decades, Nourabad City in Lorestan Province, like many cities in Iran, has experienced a rapid growth in population from 2253 people in 1966 to 71000 in 2016 . The annual growth rate in population of this city in the last 50 years has been $7.15 \%$. The important factors for this issue are high increase in natural population growth rate, rural-urban immigrations, and junction of rural settlements to formal boundaries of the city. Despite decreasing growth in the population of Nourabad in recent years, its physical growth and sprawling to the countryside villages still continues. The uncontrolled physical growth of Nourabad and its nearby villages in the last decade is mainly due to lack of a centralized management in areas that are near the cities, population inflation of the countryside villages, sprawling of the governmental organizations to the agricultural lands near the cities, and land speculation. In this regard, the present study aimed to examine the subjective and objective outcomes of annexation of rural areas near Nourabad City in the last decade.

\section{* Corresponding Author:}

Hossein Mansourian, PhD

Address: Department of Human Geography, Faculty of Geography, University of Tehran, Tehran, Iran.

Tel: +98 (916) 6607747

E-mail: h.mansourian59@ut.ac.ir 


\section{Methodology}

Our research method was descriptive and analytical. We used population data, satellite images, and researcher-made questionnaire to analyze effects and outcomes of annexing villages to the city both objectively and subjectively. Population data were provided by reports from general population and housing census. Satellite images (provided by Google Earth) were used to analyze objective changes with respect to population. Subjective effects caused by joining village to the city were assessed by a researcher-made questionnaire comprising 37 questions in different subjects, including social, economic, environmental, and physical ones. To gather subjective data, 200 subjects were randomly chosen among inhabitants of four villages and the effects of joining villages to the city were studied using subjective indicators in different aspects in their lives.

The questionnaire mainly comprised close-ended questions with answers scored by 5 -point Likert-type scale $(5=$ much better, $1=$ much worse). Afterwards questions were asked about personal and family qualifications. To evaluate internal reliability, the content validity was used to increase reliability of the questionnaire. In this method, in addition to receiving scholars and experts' opinions, the questionnaire was tested using criteria in related research. Then the designed questionnaire, in two stages, primarily and finally was filled out. By checking received answers from 40 questionnaires and doing suitable statistical calculations, the final questionnaire was designed. For final evaluation, the Cronbach $\alpha$ tool was used that was equal to 0.833 .

The descriptive statistics were used to summarize the results of the measurements. Independent sample $t$ test was used for the comparison of the averages, factor analysis was used to recognize the effects of the subjective dimensions from joining villages to city, and finally regression analysis for creating causal model to show the effects of joining villages to city. All statistical analyses were done by SPSS. In addition, Google Earth was used for preparing satellite images; and ArcGIS to handle images and observing the changes in the structure of the studied villages. Our studied region included Nourabad area in Delfan Township, Lorestan Province. This area comprised four villages; Khalife-abad, Karamabad, Kazemabad, and Cheshmakhany. These four villages joined to Nourabad area in recent decade.

\section{Results}

To analyze the social, economic, and environmental effects of joining villages to cities, different views of local residents were evaluated. In other words, the local residents were asked to evaluate the effects of joining their living environment to Nourabad City with regard to economic, social, and environmental aspects in 5-point Likert-type scale. The results show that the highest average values belonged to access to drinkable water through pipes, gas and electricity availability, quality of the construction of the buildings, and feeling security. On the other hand, the lowest average values belonged to employment, especially for the youth and women, tendency toward raising domesticated animals and poultry, diary production and motivation for activity in agricultural sector.

\section{Discussion}

The findings generally suggest that the satisfaction was high out of joining villages to cities, and according to local residential opinions positive effects were more than negative ones in this process. Some positive aspects were improvement in accessing to public services, infrastructural installations, and development in physical qualification of the village. However, we should consider its negative effects as well. For example, reduction in raising domesticated animals, and agricultural production sector, less motivation for working in these two mentioned sectors, vast changes in landscapes from agricultural to residential and commercial, were some of the most important negative effects of joining villages to city in the studied area. A total of 79 hectare agricultural lands out of these four studied villages had changed to residential areas only in recent decade. Results of this study partly confirms the results of Firooznia and colleagues (2012), Ahmadian and Ghasemi (2013), Asghari Zamani and colleagues (2013) studies.

\section{Conclusion}

Findings of the current study show that the process of joining villages to cities is a multi-dimensional process; factor analysis recognizes 8 subjective dimensions coming out of this process. Among them, physical condition of the village, production rate and motivation for activity in raising domesticated animals and working in agricultural sectors, accessing to facilities and infrastructural installations were the most important satisfying factors for joining villages to the cities. 


\section{Acknowledgments}

This research was extracted from the MSc. thesis of the third author, in the Department of Geography and Urban Planning, School of Earth Sciences, Shahid Chamran University of Ahvaz, Ahvaz, Iran.

\section{Conflict of Interest}

The authors declared no conflicts of interest. 


\title{
بررسى اثرات عينى و ذهنى الحاق روستا به شهر (مطالعه موردى: روستاهاى بير امون شهر نورآباد، (ستان لرستان)
}

\author{
مسعود صفايىيور'، "حسين منصوريان"، على كيومرثى'

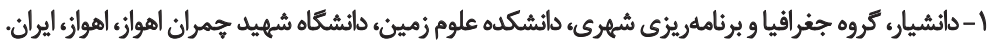

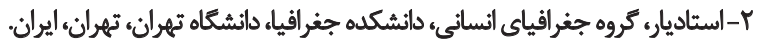

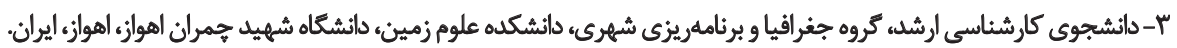

\begin{abstract}
حكيد

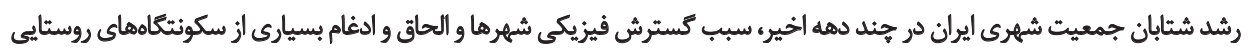

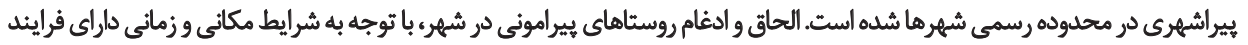

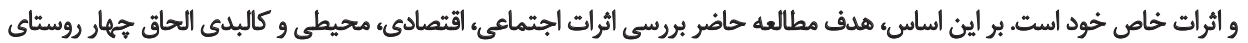

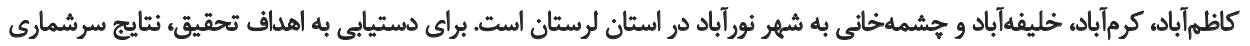

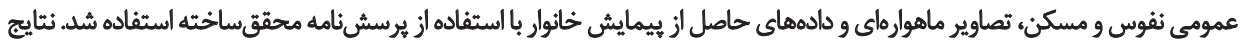

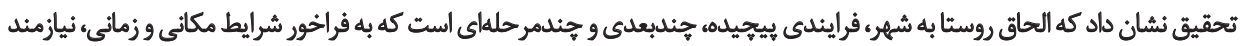

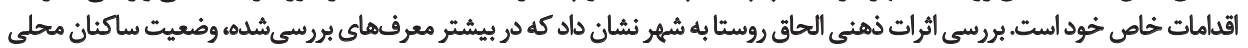

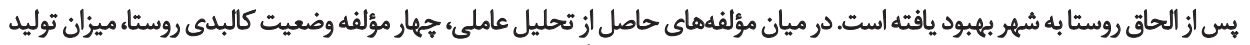

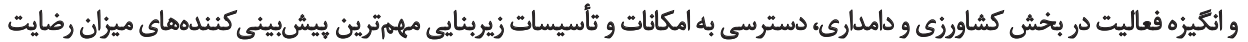
از الحاق روستا به شهر هستئد.
\end{abstract}

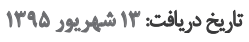

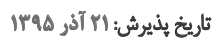

كليدوازٔها:

الحاق روسئًا به شهر، اثرات عينى و ذهنى، شهر نورآياد

و انتظار هىرود كه همه رشد آتى جمعيت در نواحى شهرى و

doles

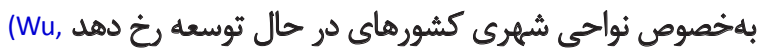
Jenerette, Buyantuyev, \& Redman, 2011; Pacione, 2011).

اكرجه شهرنشينى بديدهاى جهانى استه اين بديده به طور

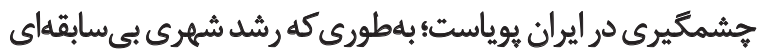

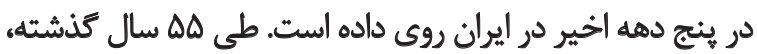

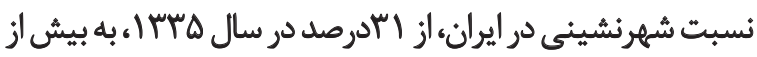

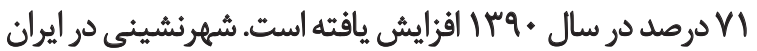

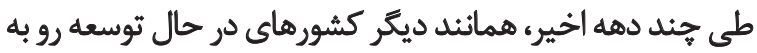

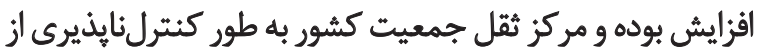

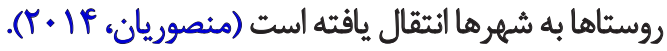
مهمترين جلوه فضايى افزايش جمعيت شهرى، رشد فيزيكى

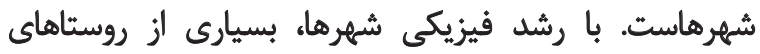

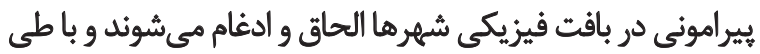

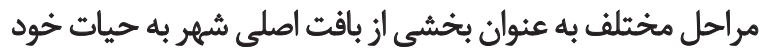

با وقوع انقلاب صنعتى در اواسط قرن 11 ميلادي، فرايند

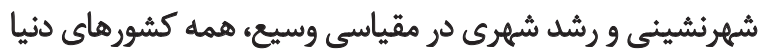

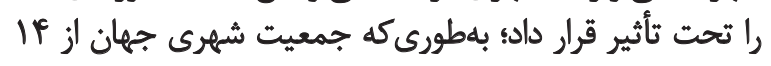

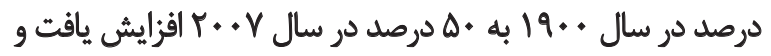

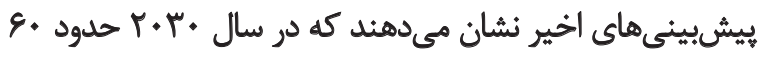

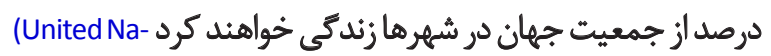

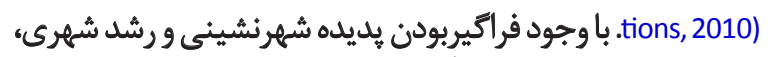

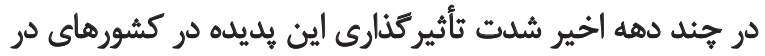

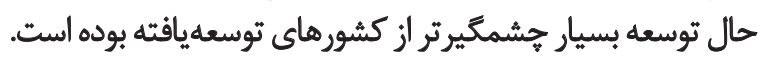

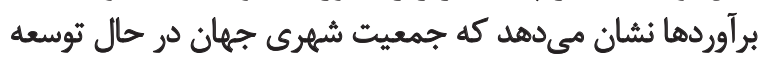

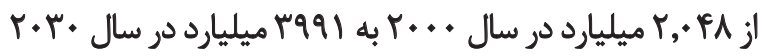

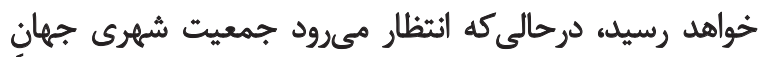

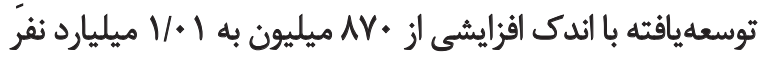

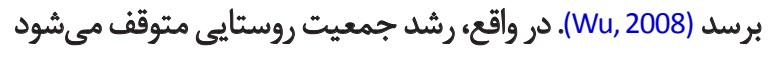
تلفن: 91 h.mansourian59@ut.ac.ir: يست الكترونيكي 
كاده است (Kong, Yin, Nakagoshi, \& James, 2012) رشد شهرى بيه

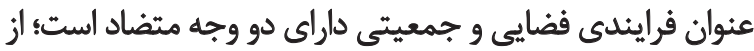

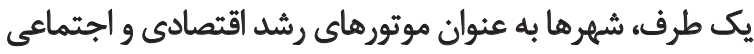

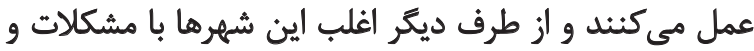

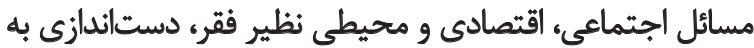

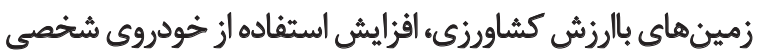
و مصرف سوخت، زوال شهر مركزى و بهرهبردارى كم از نواحيى ساختهشده فعلي مواجه هستئد.

رشد شهرى بهخصوص در شكل نامطلوب آنه يعنى براكنده-

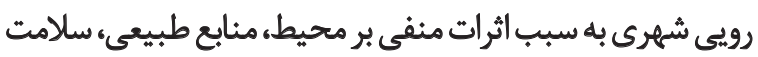

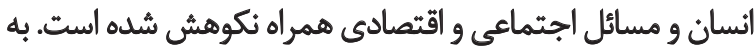

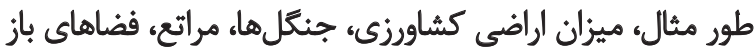

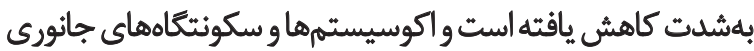

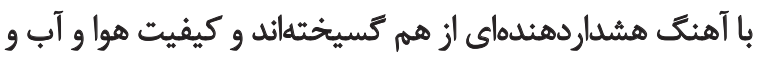

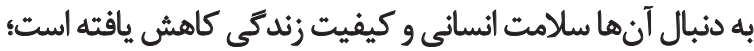

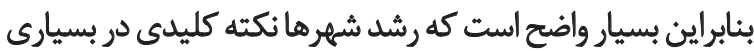

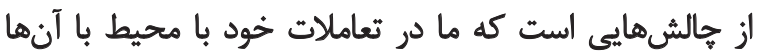

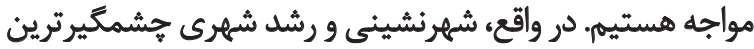

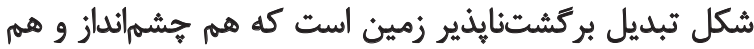

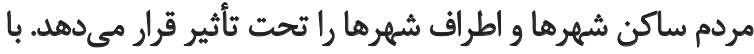
درنظركرفتن اين موضوع كه شهرنشينى با رشد شت شتابان خود، در

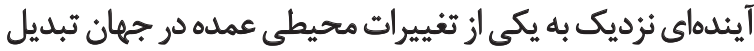

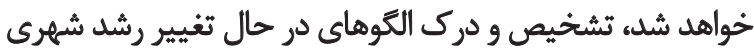
(Seto \& Fragkias, 2005). بسيار حياتى و ضرول

يكى از مهمثرين محدودهماي مكانى درهمآميختكى تحولات

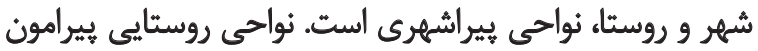

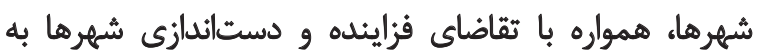

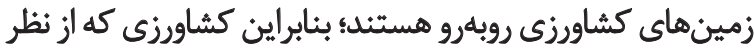

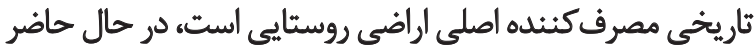

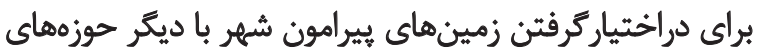

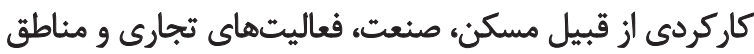

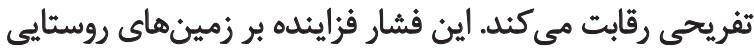

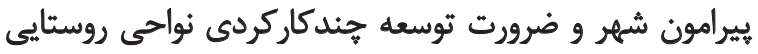

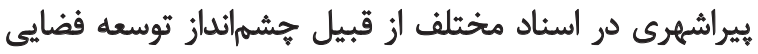

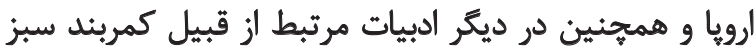

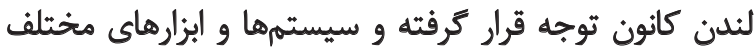

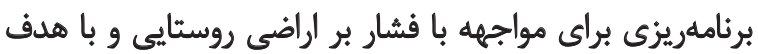

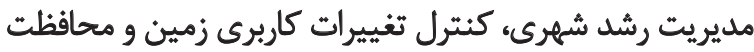

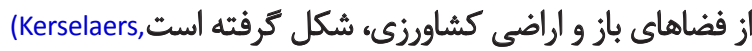

Rogge, Vanempten, Lauwers, \& Van Huylenbroeck, 2013).

غالبترين جلوه فضايى روابط ميان شهر و روستا در مناطق

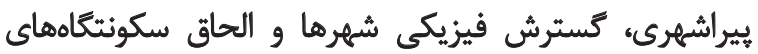

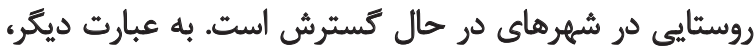

ادامه مي دهند. هطالعات متعددى در زميينه الحاق و ادغام روسيتا

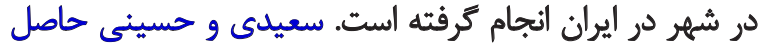

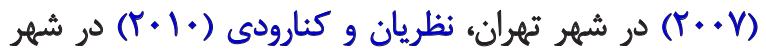

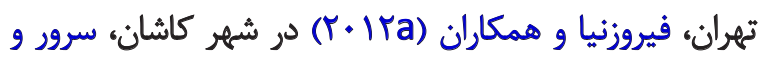

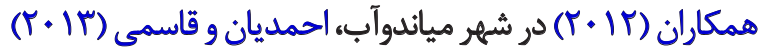

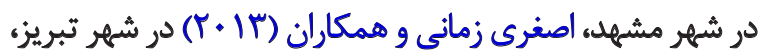

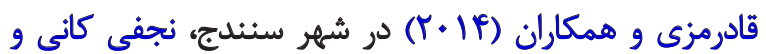

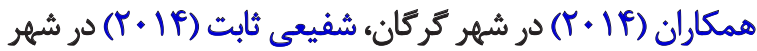

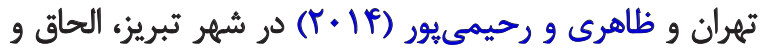

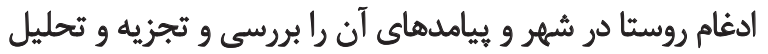

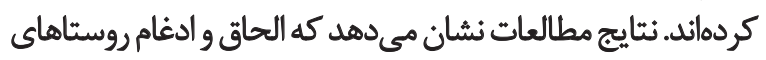

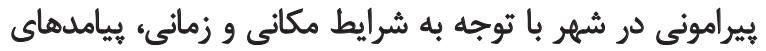

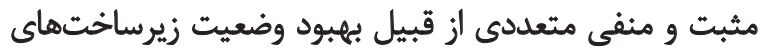

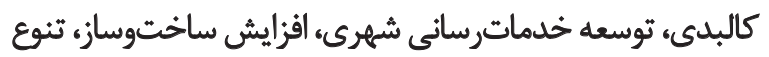

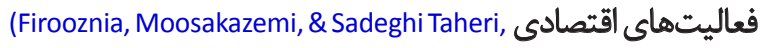

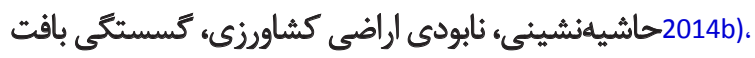

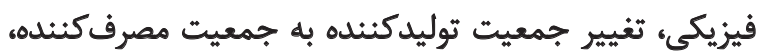

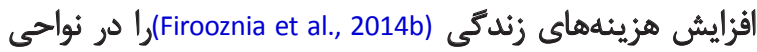
بيراشهرى به دنبال داشته استه

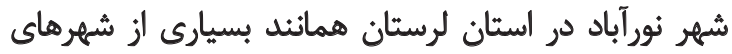

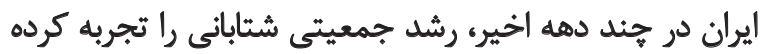

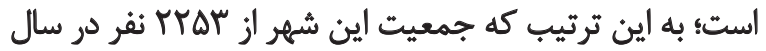

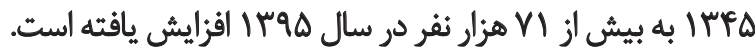

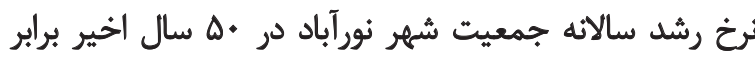

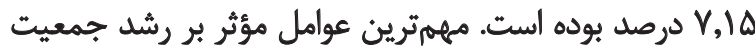

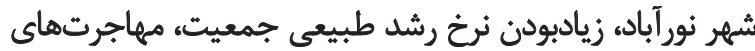

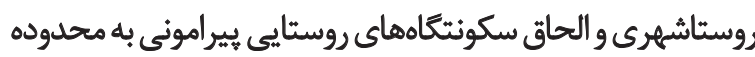

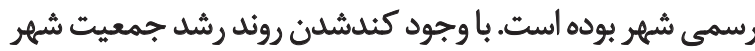

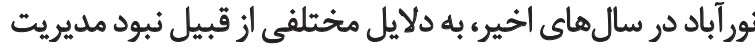

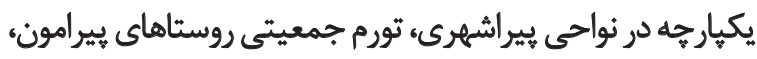

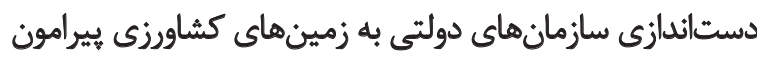

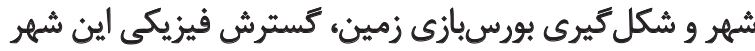

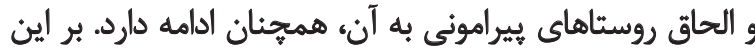

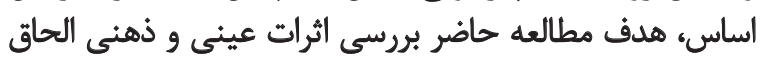

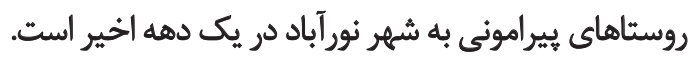

\section{مرورى بر ادبيات موضوع}

با وجود افزايش شتابان جمعيت شهرى جهان، نواحي شهرى

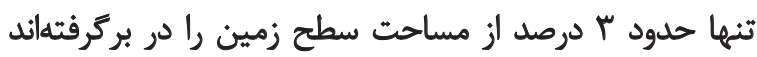

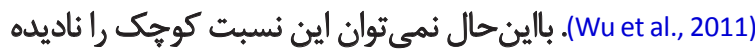

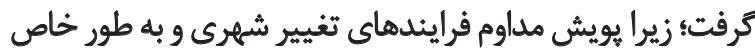

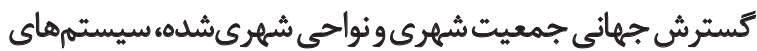

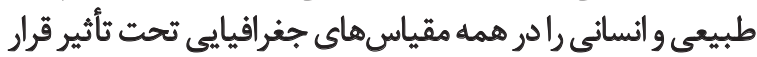




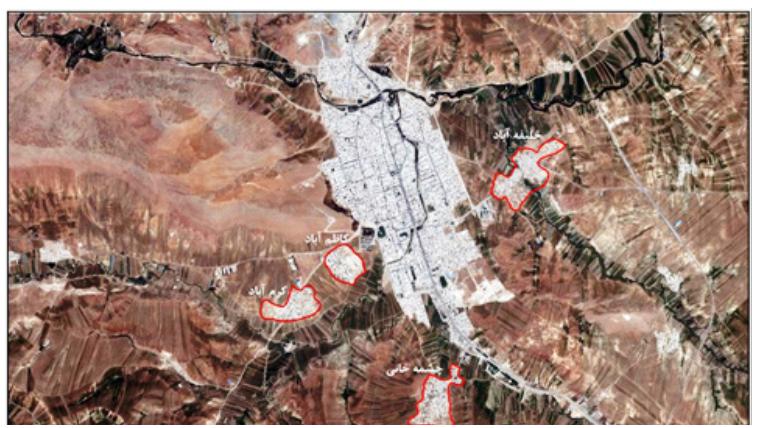

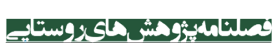

تصوير ا. محدوده مطالعششده تصقيق (Reference: Google Earth)

نمونه از ميان ساكنان جهار روستاى در حال مطالعه به صورت

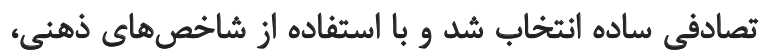

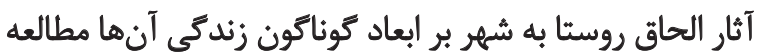

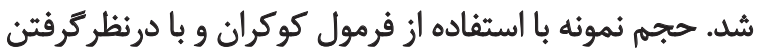

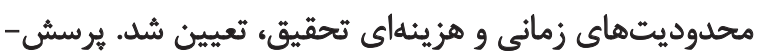

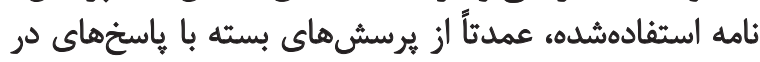

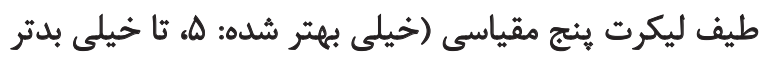

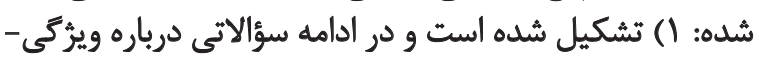

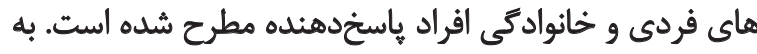

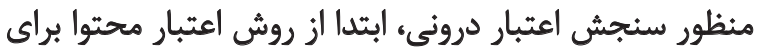

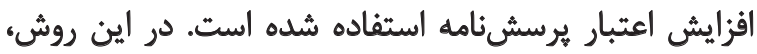

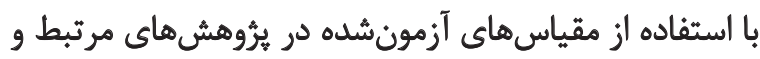

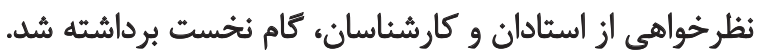

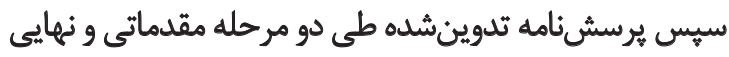

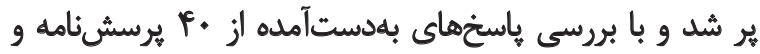

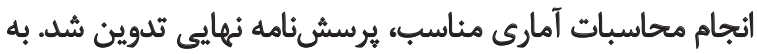

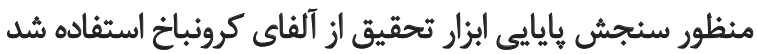

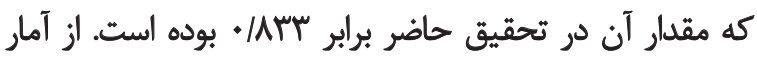

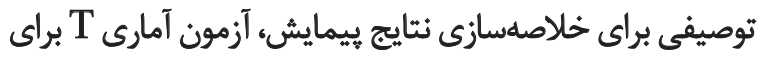

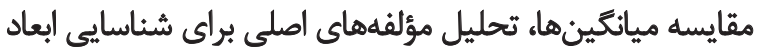

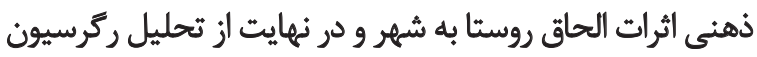

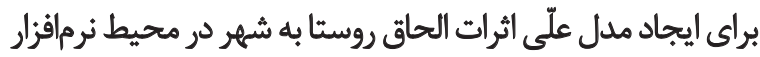

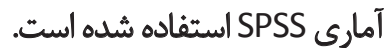

علاوه بر اين، نرمافزار Google Earth براى تهيه تصاوير

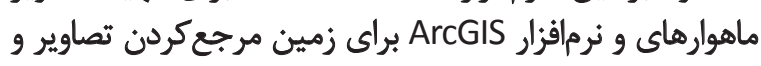

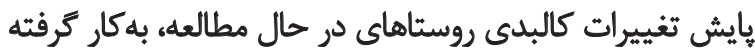

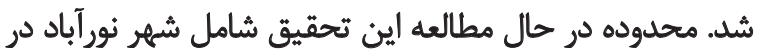

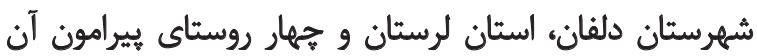

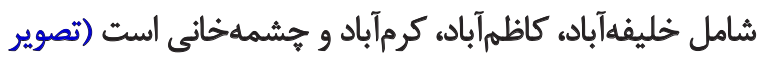

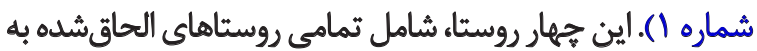
شهر نور آباد در يك دهه اخير هستئن شامل تمامى رون.
كسترش فيزيكى شهرها و روستاها به سوى يكديكر سبب الحاق

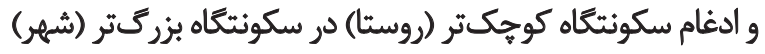

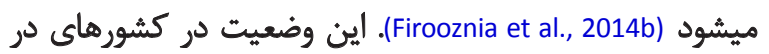

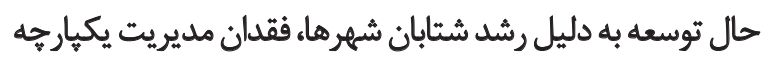

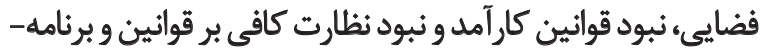

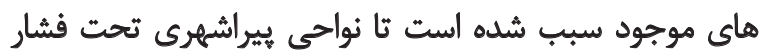

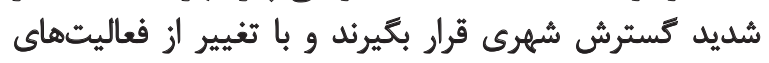
روستايى به فعاليتها و كاربرى هاى تركيبى (روستايى و شهري

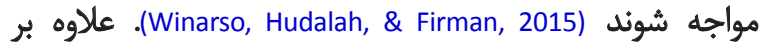
كاركردهاى در حال تغيير زمين در نواحى ثيبراشهرى و شكلدهي

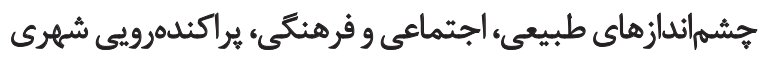

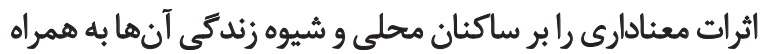
داشئه است (Zrobek-Rozanska \& Zadworny, 2016).

اين اثرات و ييامدها در غالب تغييرات سبك زندمكي، شيوه

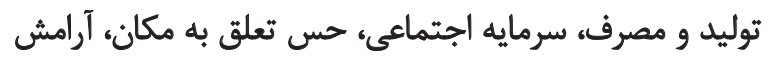

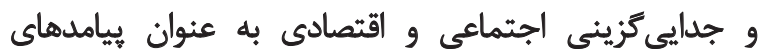

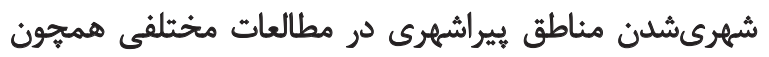

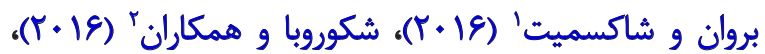

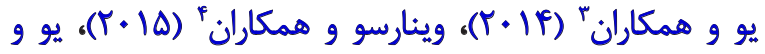

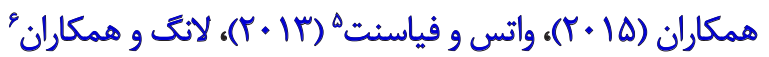

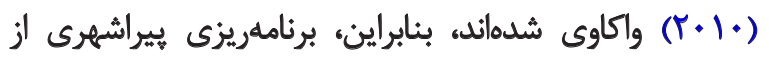

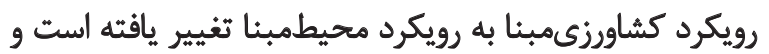

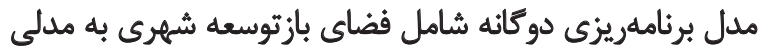

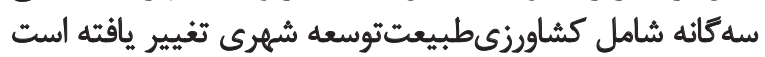
(Kerselaers et al., 2013).

\section{روش ش}

در مطالعه حاضر به منظور بررسى اثرات و بيامدهاي الحاق إن إني

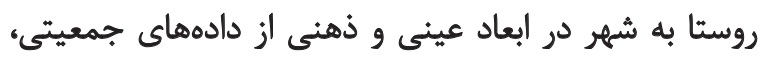

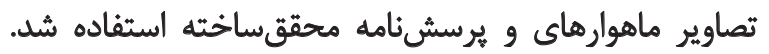

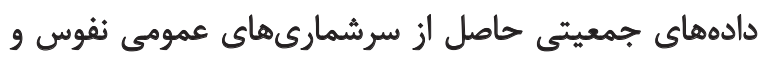

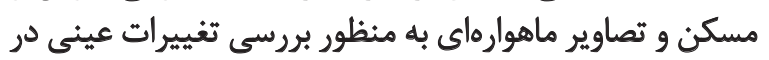

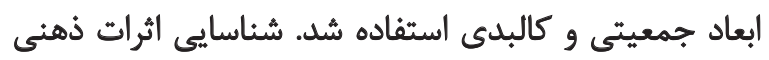

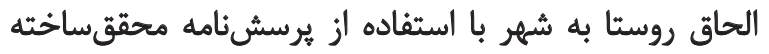

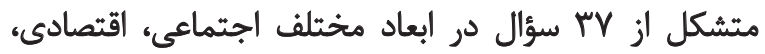

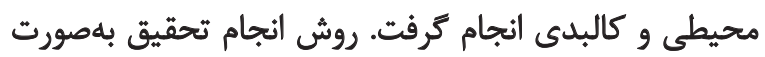

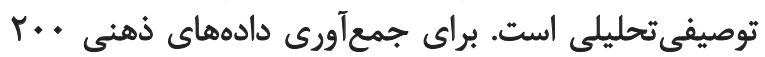

\footnotetext{
1. Brown \& Schucksmith

2. Shkaruba et al.

3. Yu et al.

4. Winarso et al.

5. Watts and Pheasant

6. Long et al.
} 


$$
\text { اثرات عينى الحاق روستا به شهر }
$$

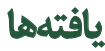

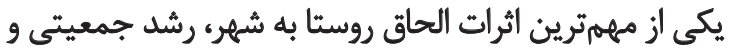

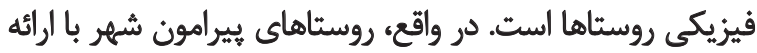

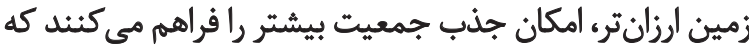

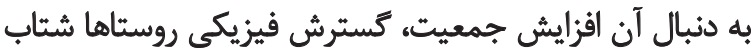

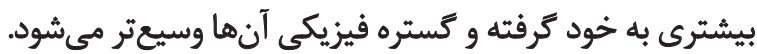

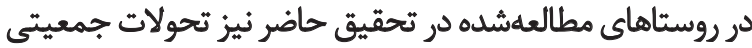

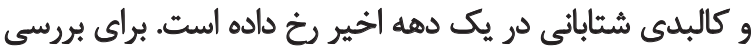

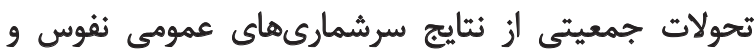

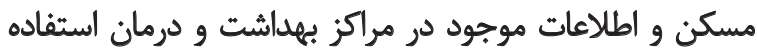

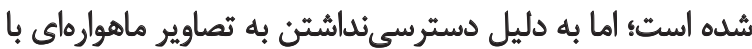

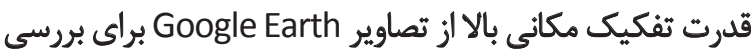

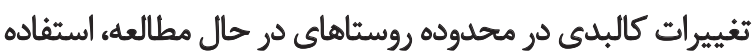

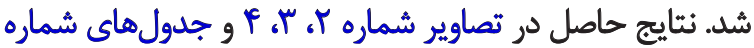

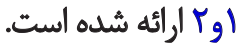

بررسى تحولات جمعيتى شهر نورآباد و روست روستاهاى

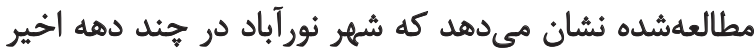

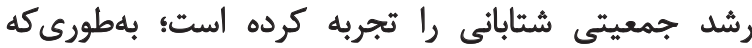

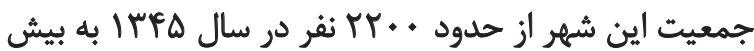

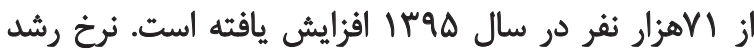

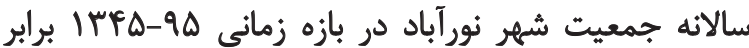

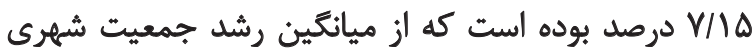

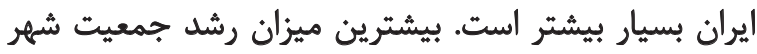

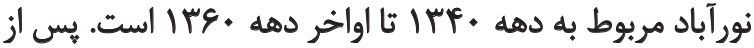

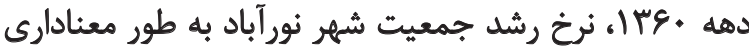

ويؤَّى هاي نمونه مطالعهشده

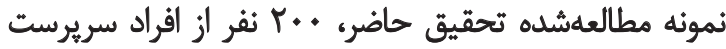

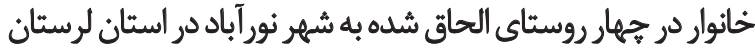

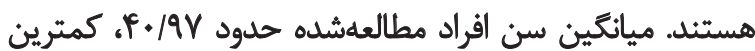

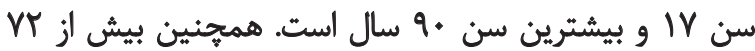

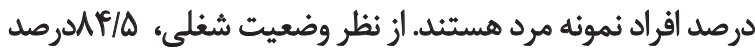

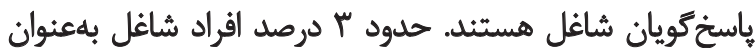

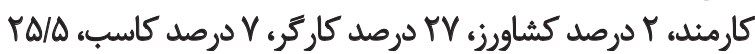

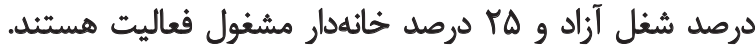

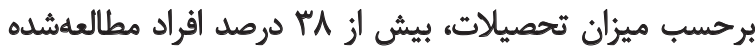

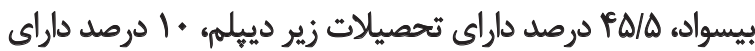

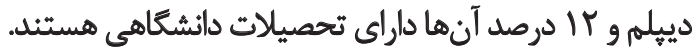
از نظر محل تولد، 19/0 درصد افراد مطالعهشده در همين دران دراند

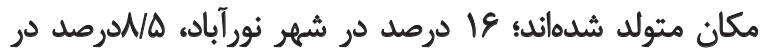

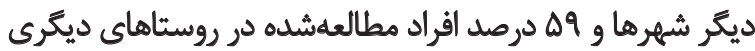

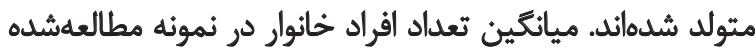

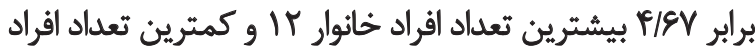

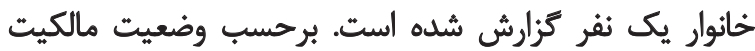

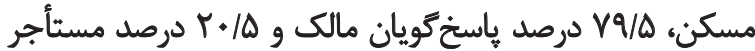

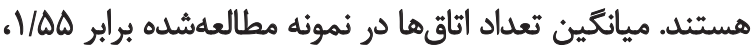

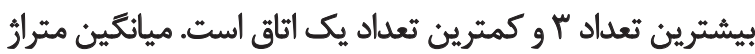

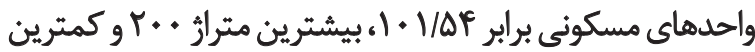

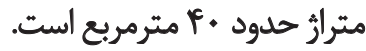

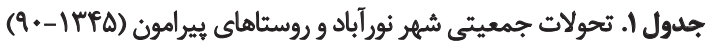

\begin{tabular}{|c|c|c|c|c|c|c|c|c|}
\hline irqs & irg. & IrAo & Irvo & Ires & IrهD & imfo & سال & شهر/روستا \\
\hline vira. & gllet & QSDT. & pqIVr & rqIM & $\Delta V^{M}{ }^{\prime}$ & rTar & جمعيت (نفر) & \multirow{2}{*}{ نور آباد } \\
\hline$r / 11$ & $1 / \Delta \Lambda$ & $1 / 4$ & $\Delta / \widetilde{\omega}$ & IT/Ar & $|f / \Delta|$ & - & نرخ رشد (درصد) & \\
\hline $19 V$ & IIAT & 9.9 & v. & DrA & fif & וسח & جمعيت (نفر) & \multirow{2}{*}{ خليفهآباد } \\
\hline$V / T$. & Q/rq & $1 / 9 V$ & $r / \Lambda \Delta$ & $r / \mathscr{L}$ & T/rg & - & نرخ رشد (درصد) & \\
\hline 1799 & $1 \% 19$ & sVG & TET & سחץ & $r \cdot \varphi$ & سF & جمعيت (نفر) & \multirow{2}{*}{ كاظهمآباد } \\
\hline $1 / T \Lambda$ & $I r / D T$ & $9 / \wedge \varepsilon$ & $-r / \mu \cdot$ & r/ar & $r / V r$ & - & نرخ رشد (درصد) & \\
\hline NFV & $\Delta Q \Lambda$ & 194 & IVF & iv. & 111 & $v^{e}$ & جمعيت (نفر) & \multirow{2}{*}{ كرمآباد } \\
\hline$N / V$ & س & $1 / \cdot 9$ & r & $r / \pi \Delta$ & $F / l F$ & - & نرخ رشد (درصد) & \\
\hline IEAT & 918 & MEV & TYA & 194 & let & - & جمعيت (نفر) & \multirow{2}{*}{ جشمه خانى } \\
\hline $\mid r / c q$ & $r I / F_{0} \Delta$ & T/R & r/ar & r/ar & - & - & نرخ رشد (درصد) & \\
\hline
\end{tabular}



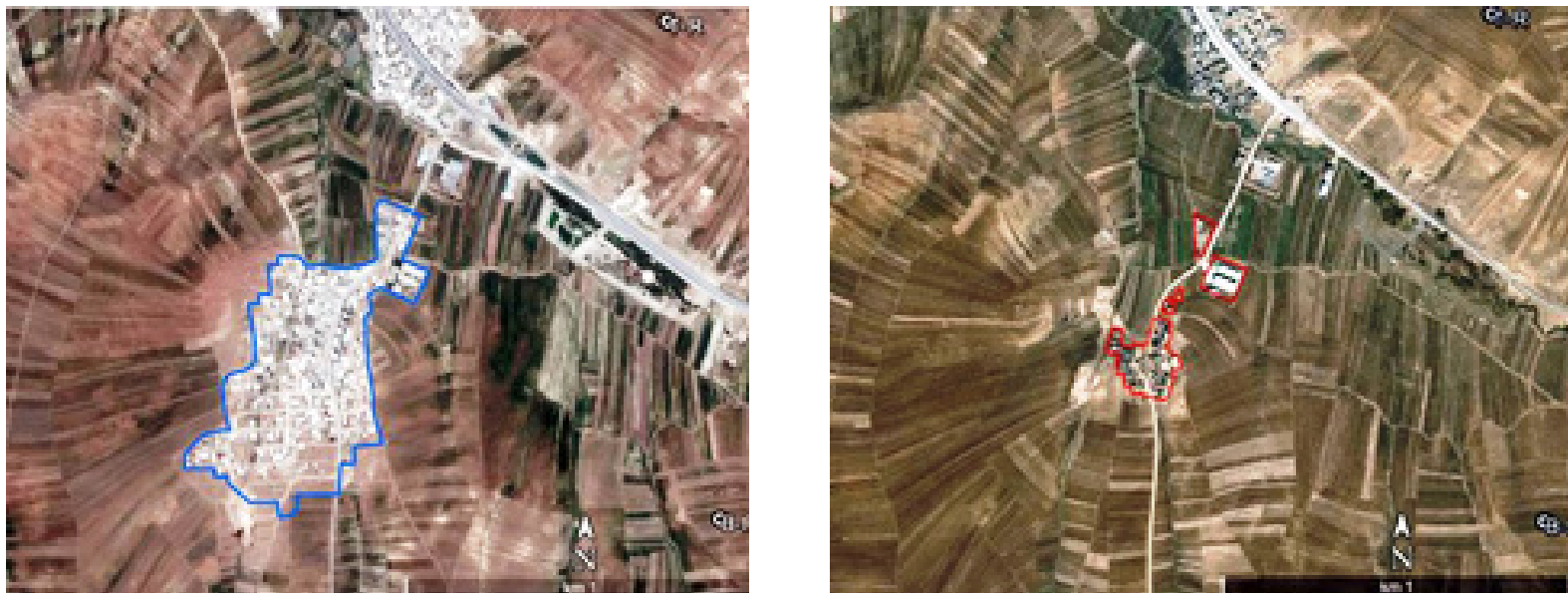

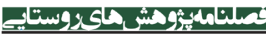

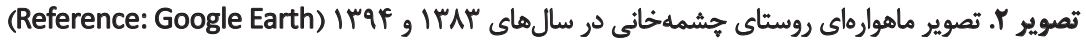

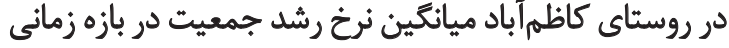
|FFD

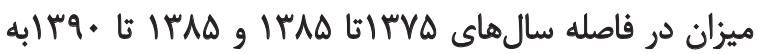

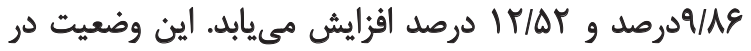

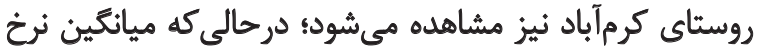

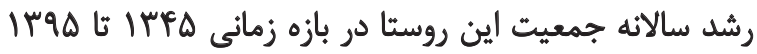

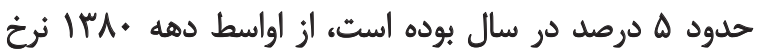

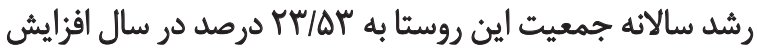

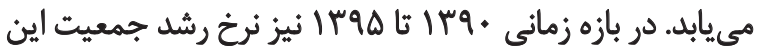
روستا برابر NVI درصد بوده است؛ كله در مقايسه بانيا ميانكين

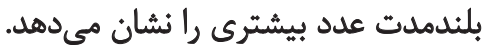

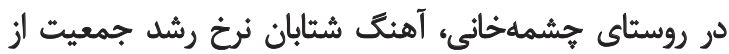

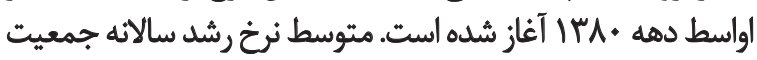

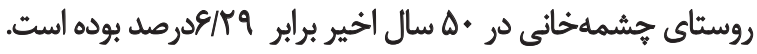

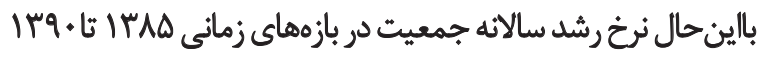

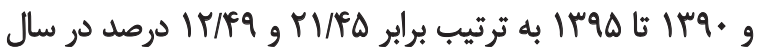

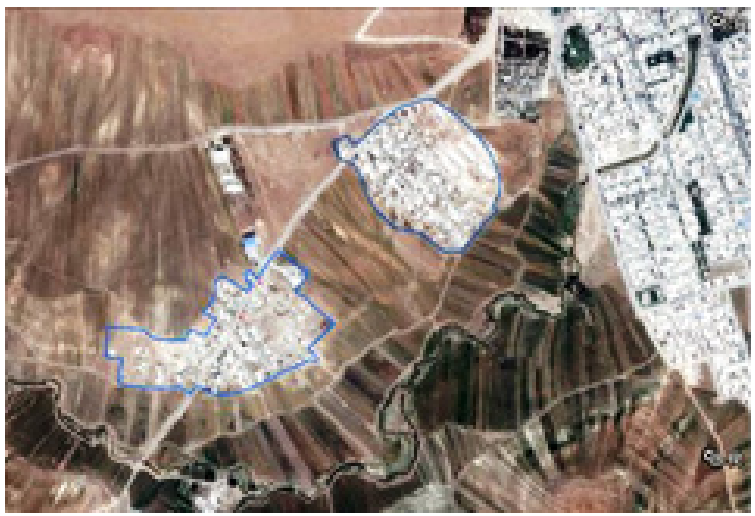

كاهش ئيدا كرده است. بالينحال در ينج سال اخير، مجددا

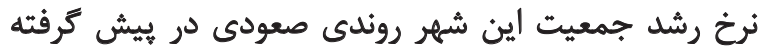

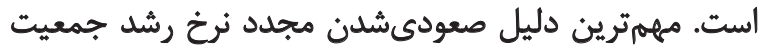

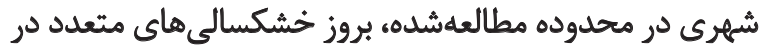

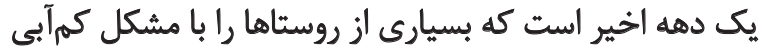

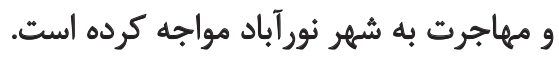

بررسى و تحليل دادهاى جمعيتى نشان ميدهد كه رشد

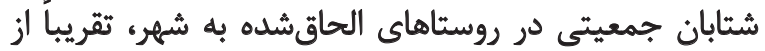

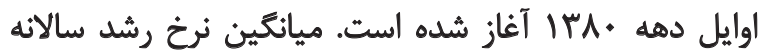

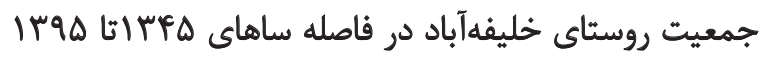

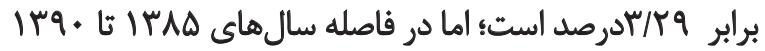

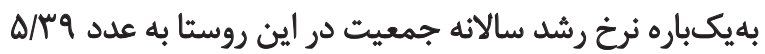

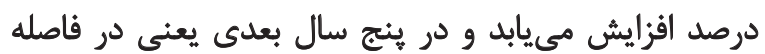

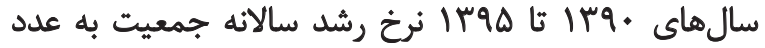

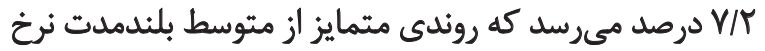

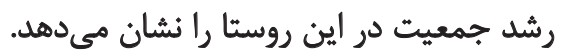

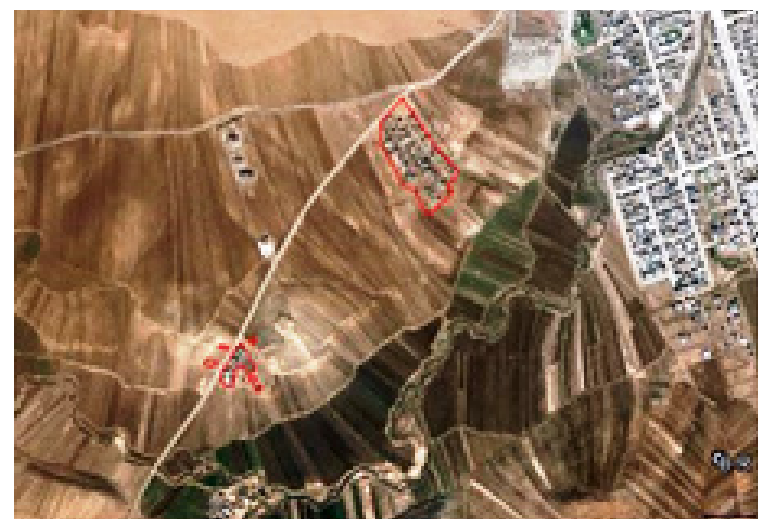



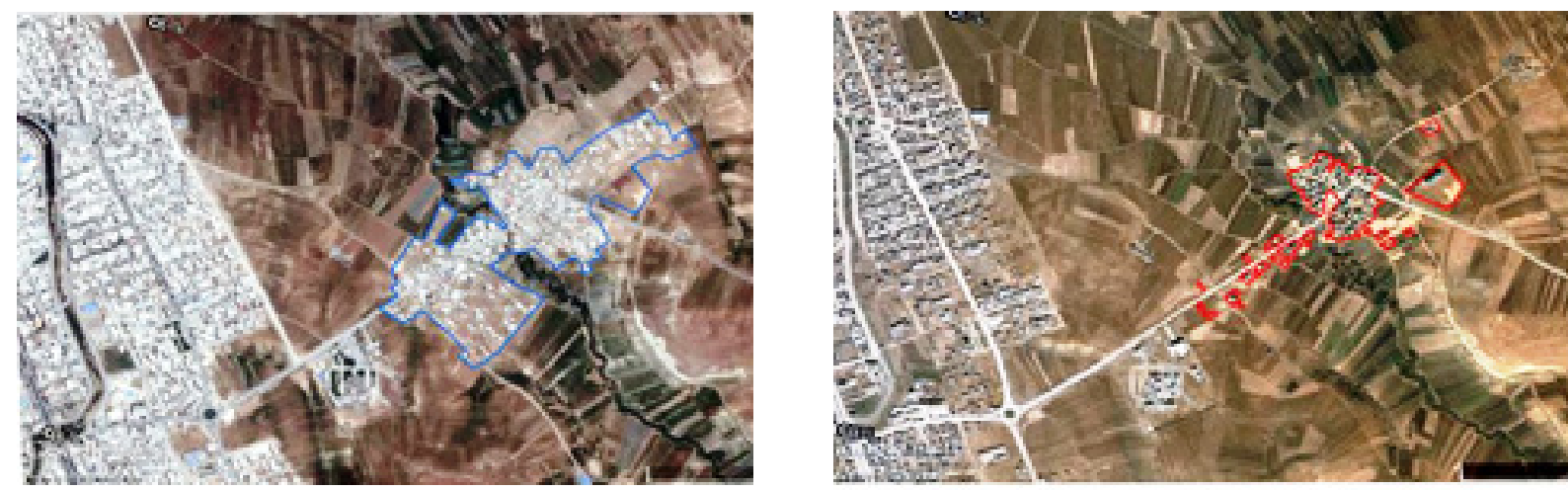

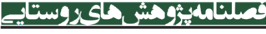

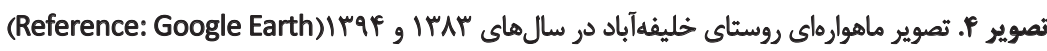

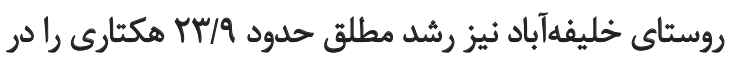

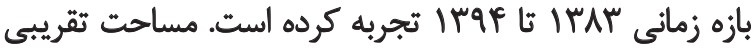

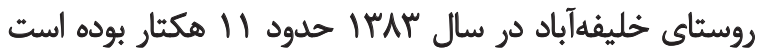

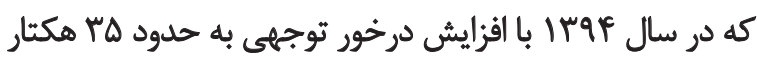

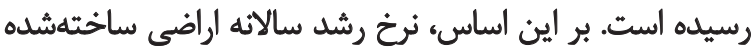

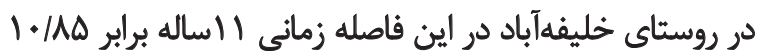
درصد در سال بوده است (تصوير شيماره أ).

به طور كلي، تغييرات فضاييزماني رشد اراضي ساختهشده

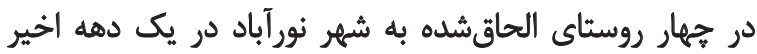
بسيار جشمكير بوده است. مساحت ثقريبي اين روستاها در سال

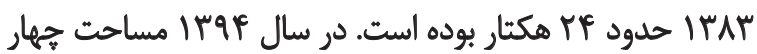

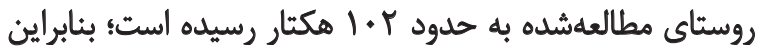

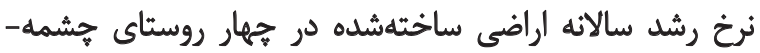

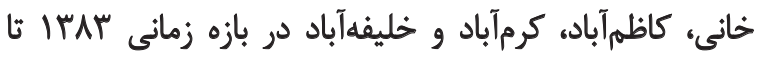

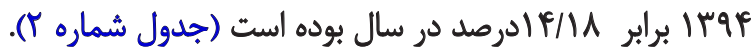

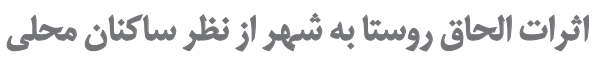

به منظور بررسى ميزان تأثيرات اجتماعى، اقتصادى و محيطى

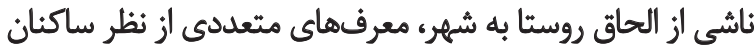

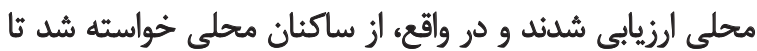

بوده است. تحولات جمعيتى شهر نورآباد و روستاهاى مطالعهشده

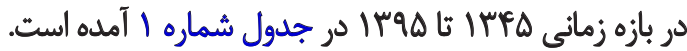
نتايج حاصل از تحليل تصاوير ماهوارهاى نشان ميدهد كه

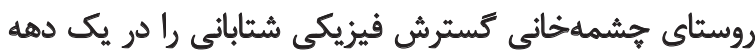

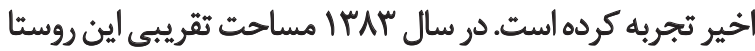

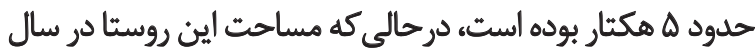

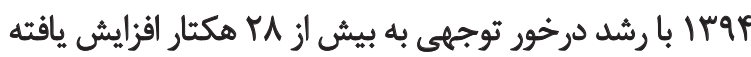

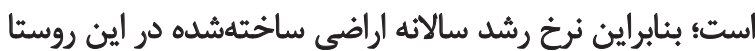

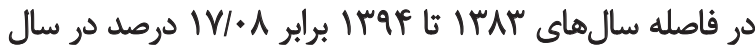

$$
\text { بوده الست (تصوير شماره باهي ساري). }
$$

شدت تغييرات فيزيكى در دو روستاي كاظهمآباد و كرمآباد

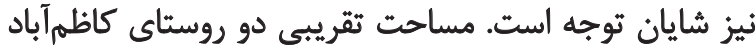

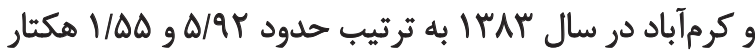

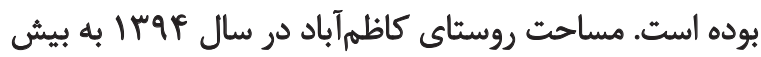

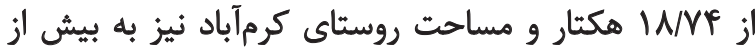

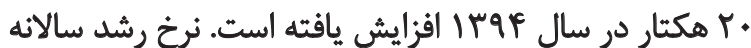

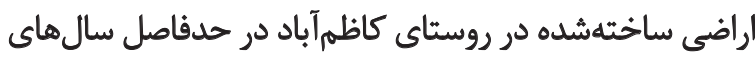
FAr معادل TR/T

\begin{tabular}{|c|c|c|c|}
\hline نتخ رقشد فيزيكى (درصد) & مساحت در سال ifaf (هكثار) & هساحت در سال بrAr I (هكتار) & ا ووبشتا \\
\hline$|V| \cdot \Lambda$ & PNTY & $\varphi / 9 q$ & جشمهنانى \\
\hline $1 . / 1 \Delta \Delta$ & $r \Delta / r$ & $11 / / V$ & خليفه|آباد \\
\hline $11 / \cdot f^{6}$ & $W^{e}$ & ब/9Y & كاظهم آباد \\
\hline TE/Tq & $r \cdot / I_{1}$ & 1/\$D & كرم/آباد \\
\hline$I F / M$ & $1 . r / \Delta r$ & $r r / A r$ & هيموع \\
\hline
\end{tabular}

جدول r. تغييرات اراضى ساختهشده در روستاهاي مطالعهشده (Irqf-IrAr) 
جدول r. نتايج بهدستآمده از آزمون مقايسه ميانكين درباره معرفهاي مربوط به تأثيرات الحاق روستا به شهر

\begin{tabular}{|c|c|c|c|c|}
\hline سطع معادارى & t & انحراف السثاندارد & مياتئين & معرف \\
\hline .1. & $-I r / r e V$ & . lase & $t / R$ & وضعيت الشتخال ساكنان \\
\hline .1. & $-9 / 998$ & $.18 \mathrm{NT}$ & $r / \Delta r$ & وضعيت درآملى ساكنان \\
\hline $.1 \circ$ & $-8 / 49$ & - MeAr & $\mathrm{r} / \mathrm{AT}$ & توزيع درآمد ميان ساكئن \\
\hline .1. & -11 /ere & ./A9Y & thet & وضعيث يسانداز خانوارها \\
\hline $.1 \%$ & $-18 / \Delta 91$ & $\cdot / \Delta V \Delta$ & T/M & فرصتهاي شعلى جديد در بخش كشاورزى \\
\hline .1. & rr/var & $\cdot / \Delta \cdot r$ & r/AQ & فرصتهاى شغلى جديد در بخش خلدمات \\
\hline$+1+$. & $-e s / u f$ &.$/ 49$ & $1 / 10$ & فرصتشاي شغلى براى جوانان \\
\hline 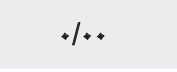 & $-81 / 494$ & . /RTH & I/IV & فرصتهاى شغلى براى زنان \\
\hline$+1+*$ & $f 1 / 4 \cdot 8$ & •/NAץ & 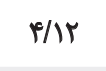 & قيمت زمين \\
\hline+1. & $r \Delta / r a A$ &.$/ M F I$ & 4 & قيمت مسكن \\
\hline+1 & $m / * 1 *$ & $\cdot / \Delta \Delta \Delta$ & $r / 9$. & وضعيت ساختوساز \\
\hline .1. & Ir/Neq &.$/ e q p$ & $r / \Delta \Delta$ & ميزان مالكيت هسكن \\
\hline .1. & $-I V / A \cdot 9$ & $.18 \cdot p^{2}$ & $T / M e$ & هيزان توليد هحصولات كشاورزى \\
\hline$\%$ & $-r \cdot / \& A V$ & - IAFA & $r / T I$ & ميزان توليد محصولات لبنى \\
\hline$\%$ & $-\Delta / \pi \nabla$ & - Nar & $r / \Delta V$ & هصرف كالاهاى لوكس و تجملى \\
\hline$\%$ & $-16 / \pi r r$ & $\cdot N \cdot 8$ & ז/Rq & انكيزه فعاليت در بخش كشاورزى \\
\hline$\%$ & $-W \cdot \Delta \Delta$ & $.18 \mathrm{VA}$ & $t / I P$ & تمايل به برورش دام و طيور \\
\hline$\%$ & IV/mer & .189. & $r / A 1$ & روابط مردم محل با يكديكر \\
\hline$+1+$ & $r+1+r q$ & $\cdot / 4 \lambda$ & $\mathrm{H} / \mathrm{r}$ & اعثماد اهالى محل نسبث به يكديكر \\
\hline$\%$ & $r \Delta / \Delta q)$ &.$/ 4 a t$ & M/AF & احساس تعلق به محيط روستا \\
\hline$*$ & ry/Arq & - IAPF & r/AF & كمك به همسايكان در حل هشكلات \\
\hline. & W/ArQ & $.18 \pi$ & $r / \Delta r$ & مشاركت در فعاليتهاي داوطلبائه \\
\hline$\%$ & TNI.1 & . IEST & $f / m$ & احساس اهنيت \\
\hline$\because, \cdot$ & WW.9 & $.18 \mathrm{~W}$ & $r / 91$ & رضايت از زئدكى \\
\hline .1. & rNTYO & - /rar & P/RY & تغيير كاربرى زمين (از كشاورزى به مسكونى) \\
\hline .1 .98 & $-1 / 8 V T$ & - /rar & r/AP & ثغيير كاربوى زمين (از كشاورزى و مسكونى به تجارى) \\
\hline .1. & ro/Ne & $.18 W$ & $P / M$ & دسترسى به أب لوله كشى بهداشتى \\
\hline$+1+$ & rV/rar &.$/ \Delta V \Delta$ & r/ar & 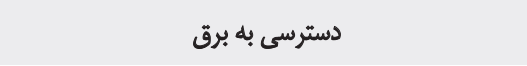 \\
\hline$+1+$ & $14 / \pi q \Delta$ & $.180 A$ & $m / g V$ & دسترسى به امكانات أموزشى \\
\hline$\cdot \pi+1$ & $-V / * r$ & $\cdot|A| A$ & $r / a f$ & دسترسي به امكائات بها:شتي درمائى \\
\hline
\end{tabular}




\begin{tabular}{|c|c|c|c|c|}
\hline سطح معنادارى & t t t t & انحراف استاندارد & مياتكين & معرف \\
\hline.+ & $-1 . / 1 \mathrm{~W}$ & $+/ N \Delta \Delta$ & $t / 4 q$ & دسترسى به فضضاهاى ثفريحى و ورزشى \\
\hline 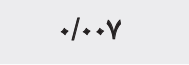 & TMYA & . MT & m/lif & دسترسى به ايثترنت \\
\hline.$\%$ & MIMTo & $\cdot / N \cdot P$ & $P / \Delta A$ & دسترسي به كاز لوله كشى \\
\hline $.1 \cdot \mathrm{rg}$ & T/MPA & $.18 q 4$ & $m / 11$ & كيفيت معابر درون و ييرامون روسثا \\
\hline$\%$ & NAEA & . NA9 & $r / \Delta$. & وضعيت جمع آلوى زباله \\
\hline 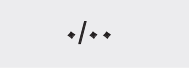 & f/NA. & $+|\& \Delta|$ & r/Tr & باكيزگى و زيبايع محيط محلى \\
\hline .1. & repris &.$(01 f$ & P/MP & 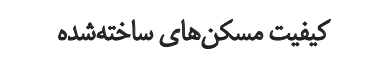 \\
\hline
\end{tabular}

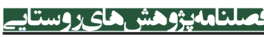

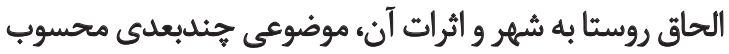

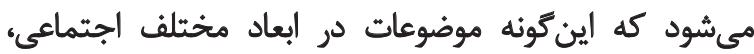

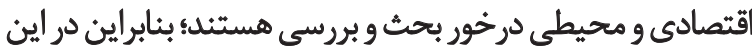

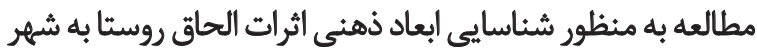

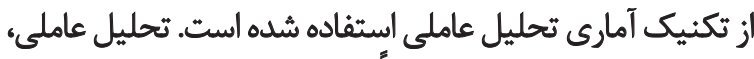

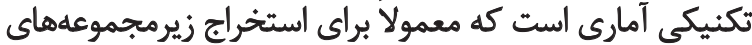

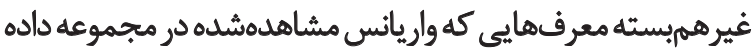

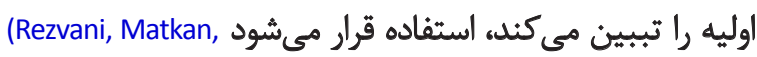
معرفهاى استفادهشه در تحليل Mansourian, \& Sattari, 2009).

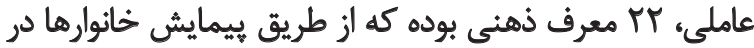

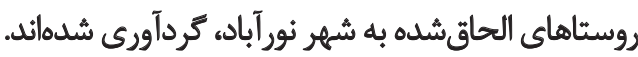

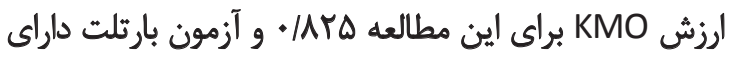

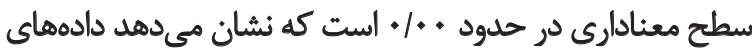

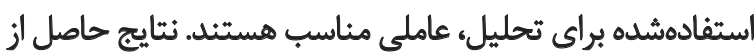

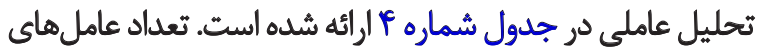

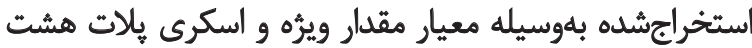

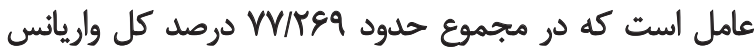

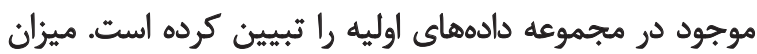

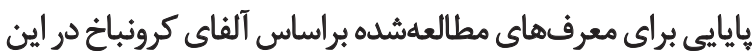

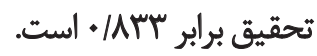

عامل نخست: اين عامل بيشترين بارهاى عاملى را با معرف-

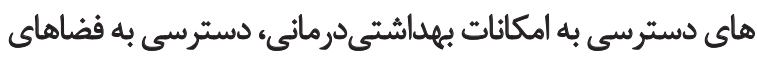

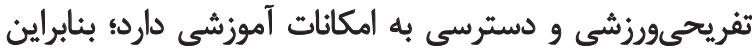

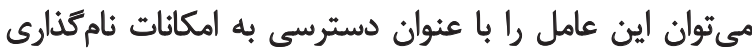

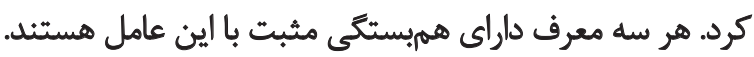

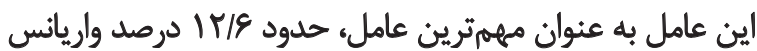

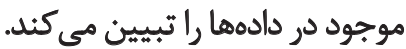

عامل دوم:اين عامل داراي بيشترين بارهاي عاملى بر معرفهاي

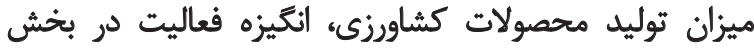
كشاورزى، ميزان توليد محصولات لبنى و تمايل به برورشات كدام و

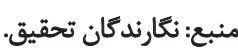

ميزان تأثيرات ناشى از الحاق محل زندگى خود رابه شيهر نور آباد در

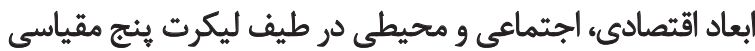

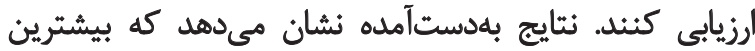

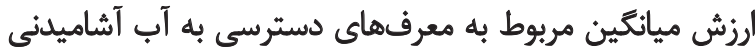

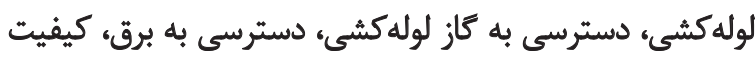

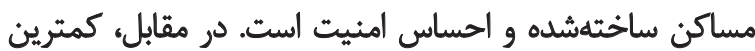

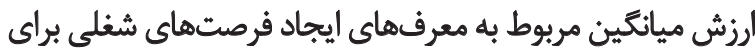

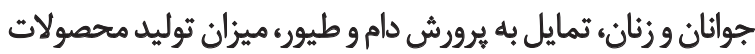

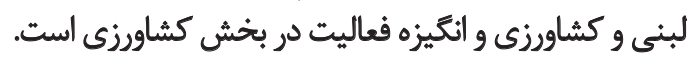
نتايج بهدستآمده از آزمون T نشان مى دهد كه از نظر ساكنان

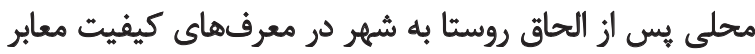

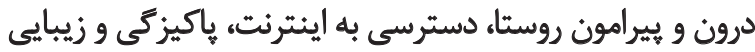

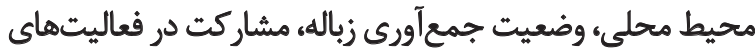

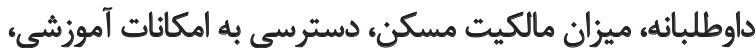

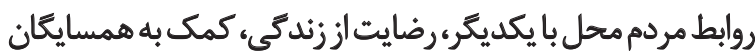

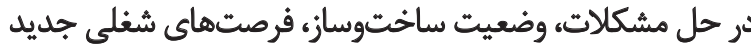

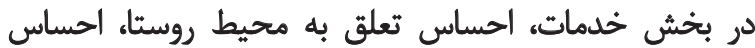

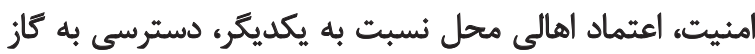

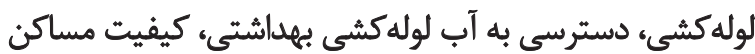

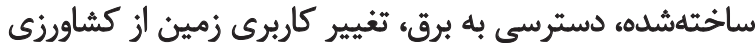

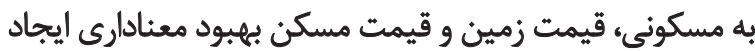

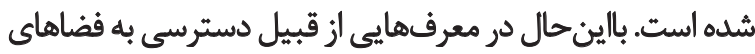

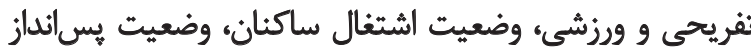

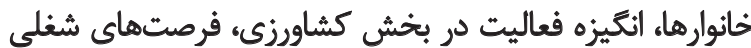

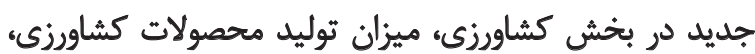

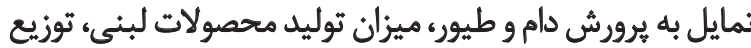

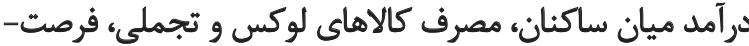

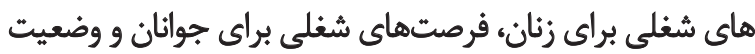

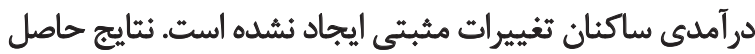
از آزمون مقايسه ميانكين در جدول شماره بـ ارائه شده است. شناسايي ابعاد ذهنى اثرات الحاق روسثا به شهر 
جدول F. ماتريس بارهاى عاملى براى شناسايى ابعاد ذهنى اثرات الحاق روستا به شهر از نظر ساكنان محلى

\begin{tabular}{|c|c|c|c|c|c|c|c|c|}
\hline \multicolumn{8}{|c|}{ 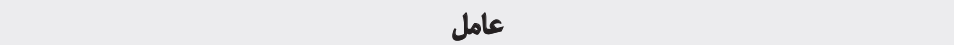 } & \multirow{2}{*}{ معرف } \\
\hline$\Lambda$ & $V$ & 8 & $\Delta$ & $P$ & $r$ & $r$ & 1 & \\
\hline & & & & & & & - MVA & دسترسى به امكائات بهياشتى درمائى \\
\hline & & & & & & & $\cdot$ MIr & دسترسى به فضاهاى تفريحىورزشى \\
\hline & & & & & & & .1898 & دسترسى به امكانات أموزشى \\
\hline & & & & & & - Neq & & توليد محصولات كشاورنى \\
\hline & & & & & &. NS1 & & ائكيزه فُعاليت در بخش كشاورزى \\
\hline & & & & & &. $\mid \Delta>1$ & & توليد محصولات لبنى \\
\hline & & & & & &.$/ 49$ & & تمايل به يرورش دام و طيور \\
\hline & & & & & - NAV & & & د الدترسى به برق \\
\hline & & & & & - Ner & & & دسترسي به أب لوله كثي \\
\hline & & & & & $\cdot N+1$ & & & دسترسى به كاز لوله كشى \\
\hline & & & & $+M$ & & & & كيفيت معابر درون و ييرامون روستا \\
\hline & & & & $\cdot / r \cdot r$ & & & & ياكيزكى و زيبائى محيط روستا \\
\hline & & & &.$/ 199$ & & & & كيقيت مسكن \\
\hline & & & $\cdot|A Y|$ & & & & & قيمت زمين \\
\hline & & & . $1 N^{2}$ & & & & & قيمت مسكن \\
\hline & &.$/ 19$ & & & & & & تغيير كاربرى زمين از كشاوززى به مسكوثى \\
\hline & &.$/ \Delta P Y$ & & & & & & وضعيت ساختوساز \\
\hline & & . AMT & & & & & & ميزان مالكيت مسكن \\
\hline &.$M I r$ & & & & & & & وضعيت اشتثال ساكنان \\
\hline & ./ब9\% & & & & & & & وضعيت درآلمد ساكنان \\
\hline$\cdot / \Lambda \Delta+$ & & & & & & & & اعتماد اهالى محل نسبت به يكديكر \\
\hline$+/ \Delta \Delta \Lambda$ & & & & & & & & احساس امنيت \\
\hline I/REN & $1 / m i$ & V/orq & IMIE & INA9 & $V / A) A$ & $1 / 94$. & $r / M e$. & مقدار ويرّها \\
\hline SMer & $N \mid \cdot 1$ & NaqY & Q/A.1 & จ/११९ & $1 . /$ Ke & $1 \cdot M \mathrm{TA}$ & IY/OTD & درصد واريانس \\
\hline & & & & W/rea & & & & مجموع واريانس ثبيين شده ( درصد) \\
\hline
\end{tabular}

\section{政}

منبع: نكارندكان تحقيق.

عامل را تحت عنوان دسترسى به ثأسيسات زيربنايى نام-

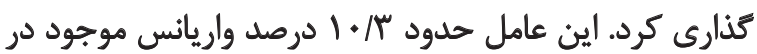

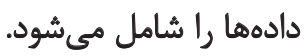

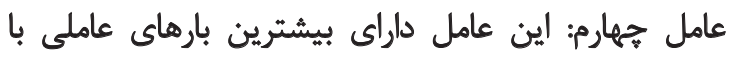

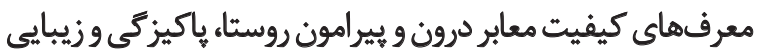

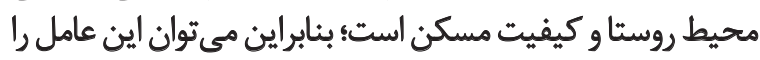

طيور است؛ بنابراين مىتوان اين عامل را باعنوان ميزان توليد و وإئ

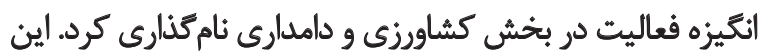

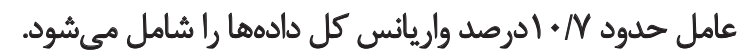

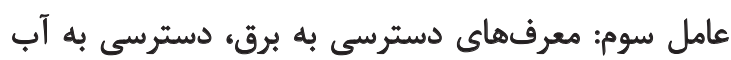

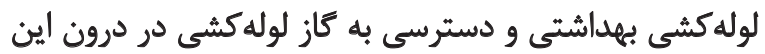

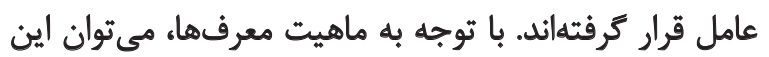


جدول ه. يبشبينى كنئدهاي رضايت از الحاق روستا به شهر

\begin{tabular}{|c|c|c|c|c|c|}
\hline سطح معنادارى & $\mathrm{t}$ & Beta & ت تعديل ياقثه & $\mathbf{R}^{r}$ & يريشينى كنتدهها \\
\hline$+1+$ & $10 / 1$ & - Mar & . Mrq & - peAr & كام نخست: وضعيت كالبدى روستا \\
\hline .1. & $\mid r / \cdot 1$ & $\cdot / N A F$ &.$/ m$ & .1818 & كام دوم: ميزان توليد و انكيزه فعاليت در بخش كشاورزى و دامعارى \\
\hline .1. & $11 / 48$ &.$/ r e$. & $.10 \cdot 1$ & $\cdot M I r$ & كام سوم: دسترسي بيه امكانات \\
\hline .1. & $1 . / 48$ &.$/ M T A$ & $\cdot 18 \cdot 9$ & - NAO & كام جهار م: دسترسي به تأسيسات زيربنايي \\
\hline .1. & NVA &.$/ T \Lambda$. &. IEAV & - AMme & كام ينجمه: اعتماد و المنيت \\
\hline. & NTE & - Tef & - Nar & $\cdot / A V^{e}$ & كام ششهم: وضعيت كثمى و كيفى مسكن \\
\hline$+1 .$. & $\Delta / M$ &.$/ 1 \notin \Delta$ & - NAP & .119 & كام هفته: الرزش زمين و مسكن \\
\hline .10 & rigr &.$/ 18$ & - Nar & ./A9V & كماه هشتم: وضعيت اقتصادى ساكنان \\
\hline
\end{tabular}

متغير وابسته و قلمروهاى هشت كانه حاصل از تحليل عاملى

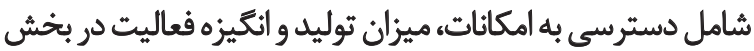

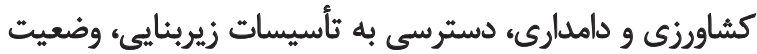

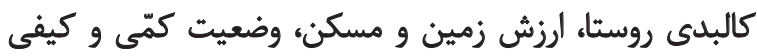

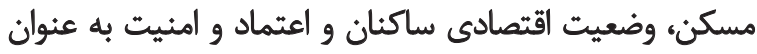

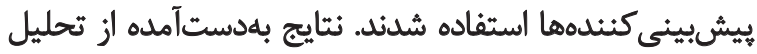
ركرسيون در جدول شماره ها ارائه شده است.

نتايج حاصل از تحليل رگرسيون به روش كامبهُام نشان

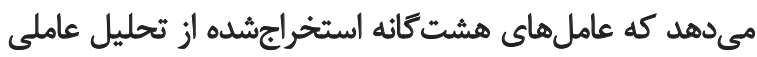

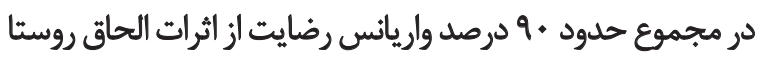

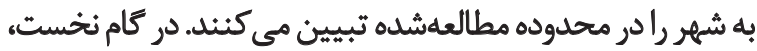

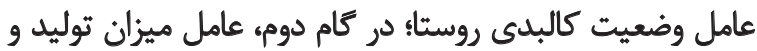

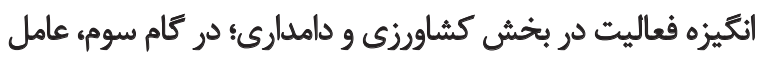

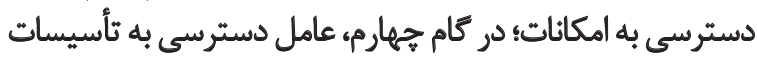

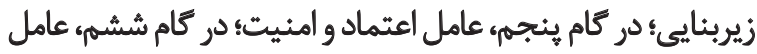

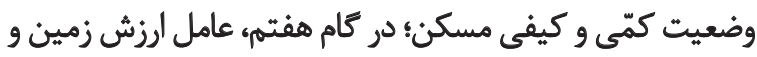

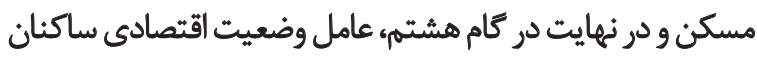

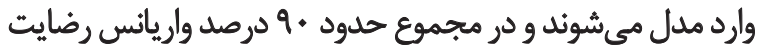
از الحاق روستا به شهر را تبيين مى مكنيند.

\section{بحث و نتيجه كيرى}

مقاله حاضر در بيى بررسى و شناسايى اثرات عينى و ذهنى

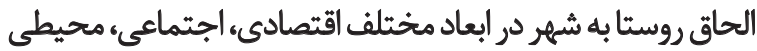

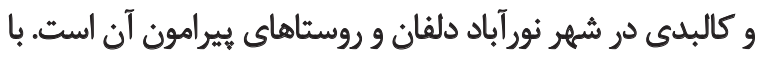

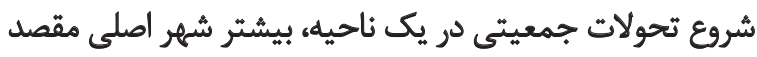

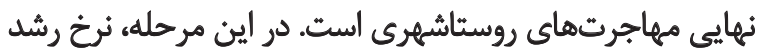

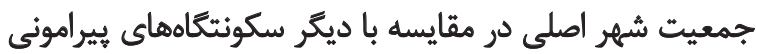

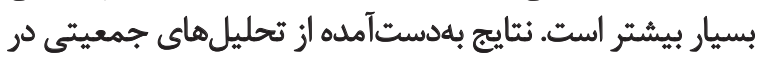

با عنوان وضعيت كالبدى روستا نامكذارى كرد. اين عامل حدود

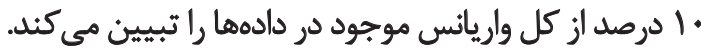

عامل بنجم: معرفهاى قيمت زمين و قيمت مسكن داراى

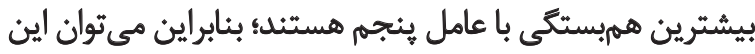

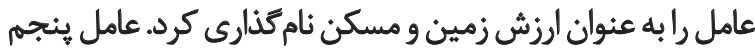
حدود 9,1 درصد واريانس دادهها را تبيين مى كندي عامل ششم: اين عامل داراى بيشترين بارهاى عاملى بامعرف-

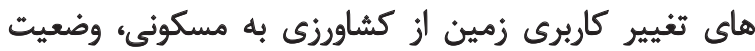

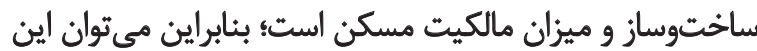

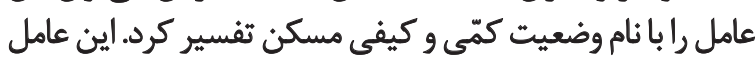
بيش از N/9 درصد واريانس موجود در دادهها را تبيين مي كني كند. عامل هفتم: اين عامل داراى بيشترين بارهاى عاملى بان

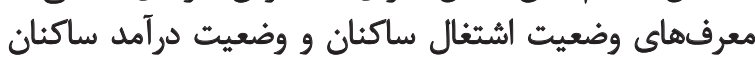

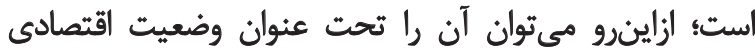

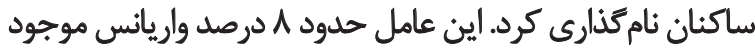

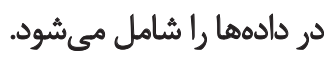

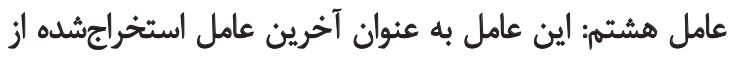

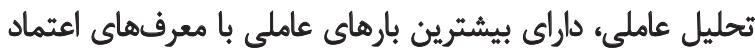

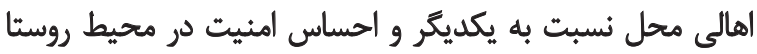

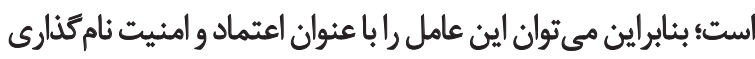

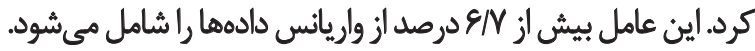

$$
\text { مدل علْى اثرات الحاق روستا به شيهر }
$$

به منظور تعيين مهرمترين ابعاد ذهنى اثرات الحاق روستا

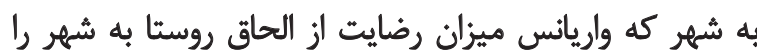

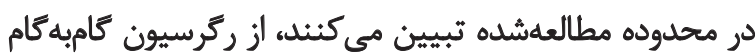

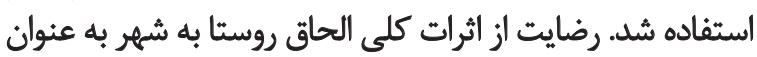




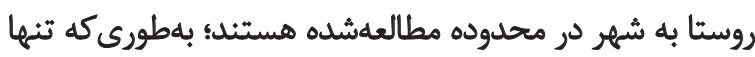

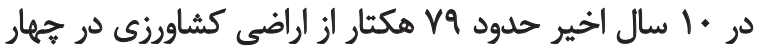
روستاى مطالعهشده به اراضى ساختهشده، تبديل شدهائد. نثايج

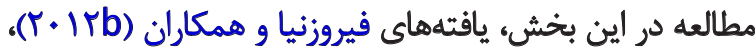

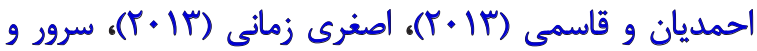

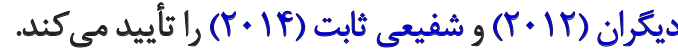

يافتههاى مطالعه حاضر، فرايند الحاق روستا به شهر را به

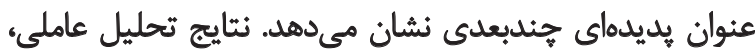

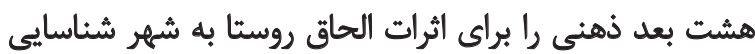

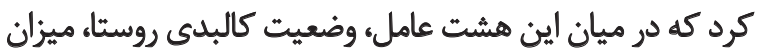

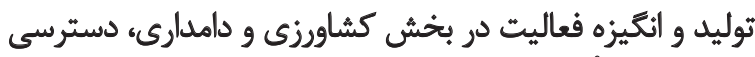

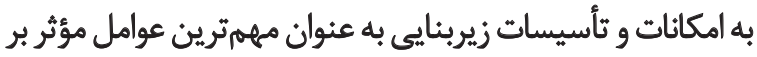

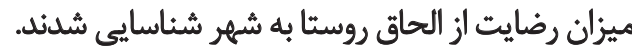
به طور كلى بايد كفت كه فرايند الحاق روستا به شهر، فرايندى "يدى

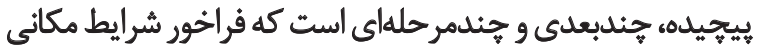
و زماني در هر مرحله نيارمند برنامهها و اقدامات متناسب استاست

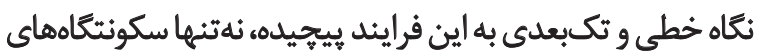

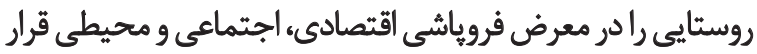

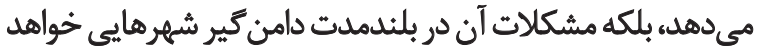

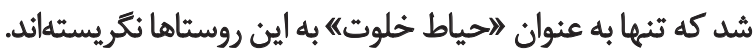

$$
\text { تشيكر و قبدرواني }
$$

اين مقاله از إياينامه كارشناسى ارشد آقاى على كيومرثى در

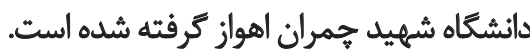

محدوده مطالعهشه نشان مي دهد كه در فاصله سال هاي تا ه

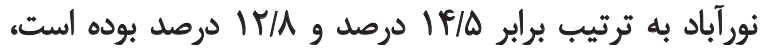

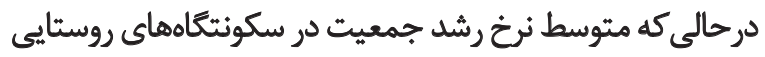

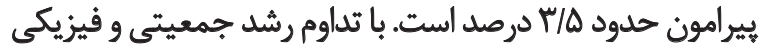

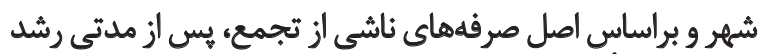

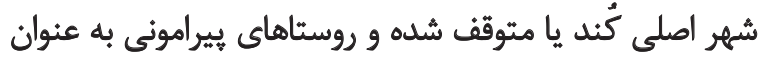

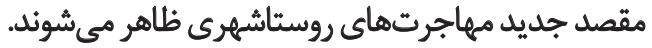

نتايج بهدستآمده از مطالعه حاضر نشان داد كه از اوايل دهد

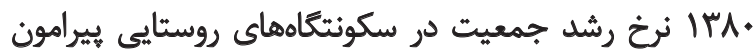

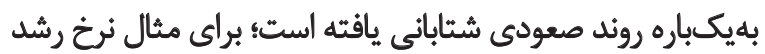

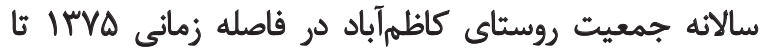

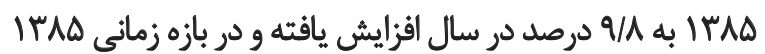

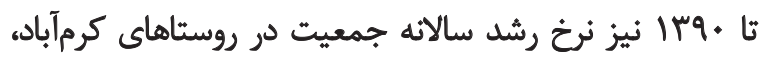

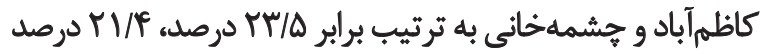

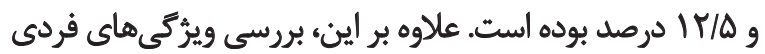

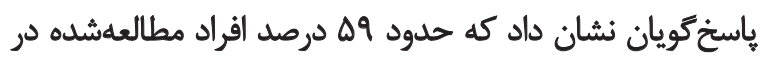

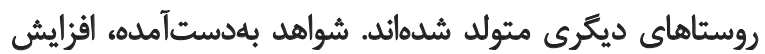

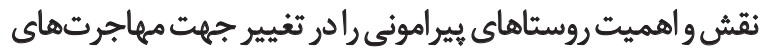

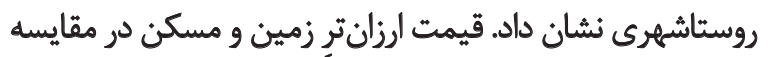

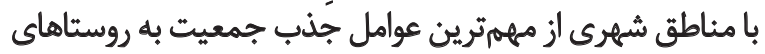
بيرامونى محسوب ميىشود.

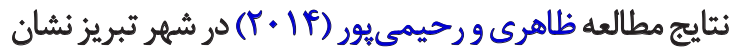

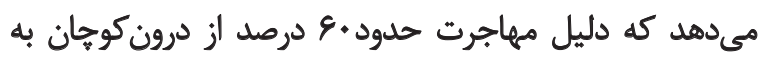

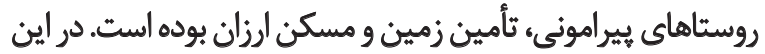

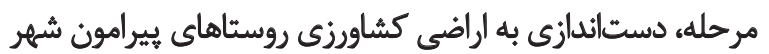

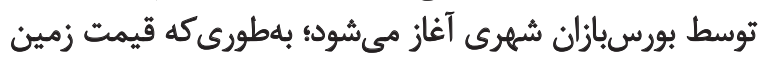

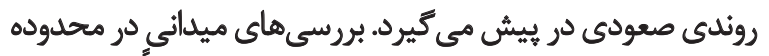

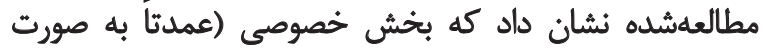

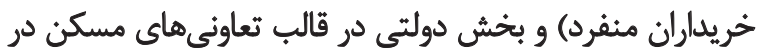

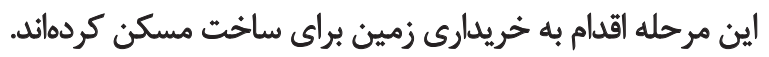

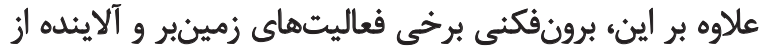

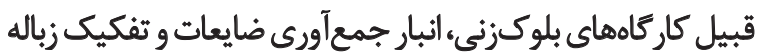

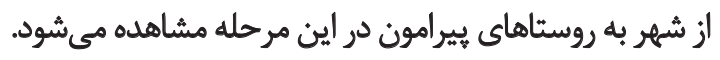

نتايج مطالعه نشان داد كه به طور كلي ميزان رضايت از اثرات

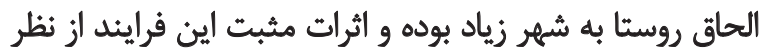

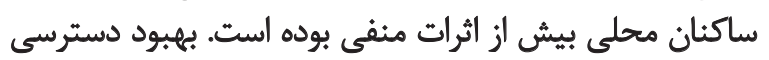

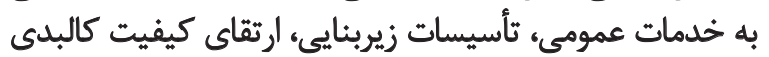

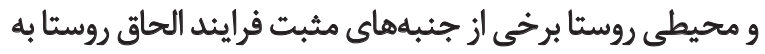

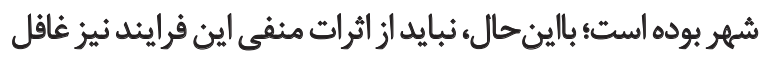

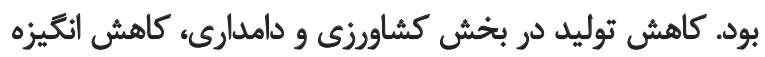

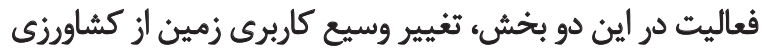

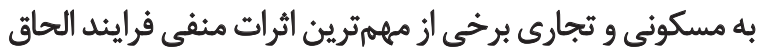




\section{References}

Ahmadyan, M. A., \& Gasemi, M. (2013). [Integration of villages in spatial-skeletal structure of cities (Case study: Mashhad) (Persian)]. Journal of Research and Rural Planning, 2(2), 143-168.

Asghari Zamani, A., Zadvali, Sh., Zadvali, F., \& Bakhshizadeh, P. (2013). [Evaluation of land use changes in villages annexed to Tabriz metropolis during the period 2002-2012 (Case study: Akhmaqaya) (Persian)]. Journal of Geography and Environmental Studies, 2(7), 35-48.

Brown, D. L., \& Schucksmith, M. (2016). A new lens for examining rural change. European Countryside, 8(2), 183-88. doi: 10.1515/ euco-2016-0015

Firooznia, G., Moosakazemi, S. M., \& Sadeghi Taheri, A. (2012a). [Analysis of distance impact on integration of rural settlements in Kashan (Persian)]. Journal of Rural Research, 2(8), 123-152

Firooznia, G., Moosakazemi, S. M., Sadeghi Taheri, A. (2012b). [Studying the impact of the integration of villages in the city (rural settlements in Kashan) (Persian)]. Quarterly Geography and Development, 9(25), 79-96.

Ghadermarzy, H., Zareh, B., \& Ziari, K. (2014). [The assessment of quality of annexed villages environment in Sanandaj (Case study: Hasanabad and Nisar (Persian)]. Quarterly Journal of Space Economy and Rural Development, 2(5), 39-56.

Kerselaers, E., Rogge, E., Vanempten, E., Lauwers, L., \& Van Huylenbroeck, G. (2013). Changing land use in the countryside: Stakeholders' perception of the ongoing rural planning processes in Flanders. Land Use Policy, 32, 197-206. doi: 10.1016/j.landusepol.2012.10.016

Kong, F., Yin, H., Nakagoshi, N., \& James, P. (2012). Simulating urban growth processes incorporating a potential model with spatial metrics. Ecological Indicators, 20, 82-91. doi: 10.1016/j.ecolind.2012.02.003

Long, H., Liu, Y., Li, X., \& Chen, Y. (2010). Building new countryside in China: A geographical perspective. Land Use Policy, 27(2), 457-70. doi: 10.1016/j.landusepol.2009.06.006

Mansourian, H. (2014). [Explaining urban growth patterns in Tehran metropolitan region (Persian)] (PhD Thesis). Tehran: University of Tehran

NajafiKani, A., Sadeghi, N., \& Rahmani, M. (2014). [Challenges and strategies regarding spatial development of the annexed villages of Gorgan (Persian)]. Quarterly Journal of Space Economy and Rural Development, 2(5), 101-118.

Nazarian, A., \& Konaroodi, S. (2010). [Social developments of integration of rural areas to spatial-physical organization of Tehran (Persian)]. Geographical Quarterly of Zagros Landscape, 2(3), 47-63.

Pacione, M. (2011). Introduction: The policy context of urbanization. In H. S. Geyer (ed.), International Handbook of Urban Policy. Cheltenham: Edward Elgar Publishing Limited. doi: $10.4337 / 9781849802024.00007$

Rezvani, M. R., Matkan, A. A., Mansourian, H., \& Sattari, M. H. (2009). [Development and assessment of indicators of urban life quality (Case study: Nurabad Delfan) (Persian)]. Urban Regional Studies and research, 1(2), 87-110.

Saeedi, A., \& Hosseini, S. (2007). [Integration metropolitan rural settlements with looking at the metropolis Tehran and around (Persian)]. Quarterly Geography, 5(12-13), 7-18.
Sarvar, R., Chatr, P., \& Kazemizad, Sh. (2012). [Study outcome of villages texture integration in city (Case study: Miandoaab) (Persian)]. Journal of Human Settlements Planning, 7(20), 43-56.

Seifodini, F. (2007). [Technical language for urban and regional planning (Persian)]. Tehran: Aeeizh Publishing

Seto, K. C., \& Fragkias, M. (2005). Quantifying spatiotemporal patterns of urban land-use change in four cities of China with time series landscape metrics. Landscape Ecology, 20(7), 871-88. doi 10.1007/s10980-005-5238-8

Shafiei Sabet, N. (2014). [Tehran metropolitan sprawl and unsustainable agriculture in the peripheral villages (Persian)]. Quarterly Journal of Environmental Based Territorial Planning, 7(24), 145-162.

Shkaruba, A., Kireyeu, V., \& Likhacheva, O. (2016). Rural-urban peripheries under socioeconomic transitions: Changing planning contexts, lasting legacies, and growing pressure. Landscape and Urban Planning. doi: 10.1016/j.landurbplan.2016.05.006

Skog, K. L., \& Steinnes, M. (2016). How do centrality, population growth and urban sprawl impact farmland conversion in Norway. Land Use Policy, 59, 185-96. doi: 10.1016/j.landusepol.2016.08.035

United Nations, Department of Economic and Social Affairs, Population Division. (2011). World population prospects: The 2010 revision, Volume I: comprehensive tables. New York: United Nations.

Watts, G. R., \& Pheasant, R. J. (2013). Factors affecting tranquillity in the countryside. Applied Acoustics, 74(9), 1094-103. doi: 10.1016/j. apacoust.2013.03.007

Winarso, H., Hudalah, D., \& Firman, T. (2015). Peri-urban transformation in the Jakarta metropolitan area. Habitat International, 49, 221-9. doi: 10.1016/j.habitatint.2015.05.024

Wu, J. (2008). Making the case for landscape ecology: An effective approach to urban sustainability. Landscape Journal, 27(1), 41-50. doi: $10.3368 / 1$ l.2.2.1.41

Wu, J., Jenerette, G. D., Buyantuyev, A., \& Redman, C. L. (2011) Quantifying spatiotemporal patterns of urbanization: The case of the two fastest growing metropolitan regions in the United States. Ecological Complexity, 8(1), 1-8. doi: 10.1016/j.ecocom.2010.03.002

Yu, A. T. W., Wu, Y., Shen, J., Zhang, X., Shen, L., \& Shan, L. (2015) The key causes of urban-rural conflict in China. Habitat International, 49, 65-73. doi: 10.1016/j.habitatint.2015.05.009

Yu, A. T. W., Wu, Y., Zheng, B., Zhang, X., \& Shen, L. (2014). Identifying risk factors of urban-rural conflict in urbanization: A case of China. Habitat International, 44, 177-85. doi: 10.1016/j.habitatint.2014.06.007

Zaheri, M., \& Rahimpoor, B. (2014). [The survey of the effecting factors on the functional changes of rural settlements in the influence of metropolitan zones (Case study: Biragh, Heravi, Haj Abdol, and Dizaj Leyli Khani Villages located in Lyghvan valley, East Azerbaijan) (Persian)]. Journal of Housing and Rural Environment 33(146), 121-39.

Źróbek-Różańska, A., \& Zadworny, D. (2016). Can urban sprawl lead to urban people governing rural areas? Evidence from the Dywity Commune, Poland. Cities, 59, 57-65. doi: 10.1016/j.cities.2016.06.003 


\title{
Research Paper \\ Content Analysis of Articles in Journal of Rural Research From 2010 to 2016
}

\author{
Behnaz Sadat Bashiri ${ }^{1},{ }^{*}$ Mohammad Amin Khorasani ${ }^{2}$
}

1. MSc. Student, Department of Human Geography, Faculty of Geography, University of Tehran, Tehran, Iran.

2. Assistant Professor, Department of Human Geography, Faculty of Geography, University of Tehran, Tehran, Iran.

Received: 08 Aug. 2016 Accepted: 19 Feb. 2017

Keywords:

Content analysis, Articles, Journal of rural research, Rural studies, Iran ditat on: Bashiri, B. S., \& Khorasani, M. A. [Content Analysis of Articles in Journal of Rural Research From 2010 to 2016 (Persian)]. Journal of Rural Research, 8(1), 138-151. http://dx.doi.org/10.21859/jjr-08019

: http://dx.doi.org/10.21859/jjr-08019

\begin{abstract}
Journals are considered as one of the main forms of knowledge transfer in scientific research and in the international community have their own spotlights. According to the progress of scientific articles, scientific-research journals, as one of most attainable citation sources are always used by researchers and students. Content analysis method enables the researcher to obtain expression and critical evaluation of research projects, regardless of their results. Journal of Rural Research is one of the scientific publications in the field of rural issues that started its career in 2010 aimed at disseminating basic and applied research in the field of rural studies with the innovative and high-quality interdisciplinary approach. All studies in the field of geographical sciences were the spatial nature allocated to a part of land as the study area. Accordingly, most studies specified a range from small to large scale divisions. Provincial scattering studies are on the map. Kermanshah province, Iran, with 29 articles is in the first place. Then Kurdistan (14), Isfahan, and Tehran (13) are in the follows, respectively. The provinces of Qom, Ardebil, with up to 2 papers had lowest benefited. The results of the current study showed that although the number of female writers in 6 periods had a rising trend, generally about one-third of the writers were female and other two-thirds were males. According to the provincial dispersions, Qom and Ardebil provinces had paid less attention to the need to achieve the status of villages in the areas and more studies should be done on them.
\end{abstract}

\section{Extended Abstract}

\section{Introduction}

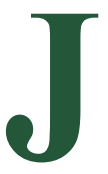

ournals are considered as one of the main forms of knowledge transfer in scientific research and in the international community have their own spotlights; therefore, inventions, discoveries, and new findings can be found in the framework of these specific avenues of information that are specialized as much as possible. According to the progress of scientific articles, scientific-research journals, as one of most attainable citation sources, are always used by researchers and students. Therefore, they can be called as basic references of scientific topics. Given the importance of the role of scientific journals in the production and development of science, content analysis of journals can reveal clearly the status quo. Research questions include:

1. What are the trends of articles published in the Journal?

2. What is the gender ratio of the contribution of authors?

3. What is the distribution of disciplines and specialty of authors?

\footnotetext{
* Corresponding Author:

Mohammad Amin Khorasani, PhD

Address: Department of Human Geography, Faculty of Geography, University of Tehran, Tehran, Iran.

Tel: +98 (21) 61113526

E-mail: khorasani_ma@ut.ac.ir
} 